\title{
(2) OPEN ACCESS \\ Guidelines on the use of liver biopsy in clinical practice from the British Society of Gastroenterology, the Royal College of Radiologists and the Royal College of Pathology
}

\author{
James Neuberger (D) , ${ }^{1}$ Jai Patel, ${ }^{2}$ Helen Caldwell, ${ }^{3}$ Susan Davies, ${ }^{4}$ Vanessa Hebditch, ${ }^{5}$ \\ Coral Hollywood, ${ }^{6}$ Stefan Hubscher, ${ }^{7}$ Salil Karkhanis, ${ }^{8}$ Will Lester, ${ }^{9}$ Nicholas Roslund, ${ }^{10}$ \\ Rebecca West, ${ }^{5}$ Judith I Wyatt, ${ }^{11}$ Mathis Heydtmann ${ }^{12}$
}

- Additional material is published online only. To view please visit the journal online (http://dx.doi.org/10.1136/ gutjnl-2020-321299).

For numbered affiliations see end of article.

\section{Correspondence to}

Dr James Neuberger, Liver Unit, University Hospitals Birmingham NHS Foundation Trust, Birmingham B15 2PR, UK jamesneuberger@hotmail.co.uk

Received 2 April 2020 Revised 23 April 2020 Accepted 24 April 2020 Published Online First 28 May 2020
Check for updates

(C) Author(s) (or their employer(s)) 2020. Re-use permitted under CC BY-NC. No commercial re-use. See rights and permissions. Published by BMJ.

To cite: Neuberger J, Patel J, Caldwell $\mathrm{H}$, et al. Gut

2020:69:1382-1403.

\begin{abstract}
Liver biopsy is required when clinically important information about the diagnosis, prognosis or management of a patient cannot be obtained by safer means, or for research purposes. There are several approaches to liver biopsy but predominantly percutaneous or transvenous approaches are used. A wide choice of needles is available and the approach and type of needle used will depend on the clinical state of the patient and local expertise but, for nonlesional biopsies, a 16-gauge needle is recommended. Many patients with liver disease will have abnormal laboratory coagulation tests or receive anticoagulation or antiplatelet medication. A greater understanding of the changes in haemostasis in liver disease allows for a more rational, evidence-based approach to peribiopsy management. Overall, liver biopsy is safe but there is a small morbidity and a very small mortality so patients must be fully counselled. The specimen must be of sufficient size for histopathological interpretation. Communication with the histopathologist, with access to relevant clinical information and the results of other investigations, is essential for the generation of a clinically useful report.
\end{abstract}

\section{EXECUTIVE SUMMARY}

Histopathological interpretation of a liver biopsy is indicated when information for diagnosis, management, treatment or prognostication is not available from non-invasive techniques. Liver biopsy is also indicated for research purposes where there is appropriate ethics approval and consent.

Patient consent should be obtained prior to the biopsy. Information provided should include the benefits and risks of liver biopsy, alternatives where appropriate, and follow-up arrangements. The information should be given verbally and supplemented with written information in a format that is understandable by the patient and, where appropriate, their carers. Where possible, this information should be given several days before the biopsy by a healthcare practitioner who is familiar with the techniques and with enough time for the patient to ask questions. Consent should be confirmed immediately prior to the biopsy.
Risks of percutaneous liver biopsy include bleeding, organ perforation, sepsis and death. Bleeding occurs in up to $10 \%$ with major bleeding occurring in less than 2\%. Risk factors for bleeding from percutaneous biopsy include older age, comorbidities, indication for biopsy and coagulation. There is little conclusive evidence that operator status and number of passes significantly affects the risk of bleeding. Mortality associated with biopsy is less than 1 in 1000 .

Haematological parameters in many patients with liver disease are abnormal, with disturbance of both thrombolysis and coagulation; the traditional measures of platelet count and prothrombin time do not give an accurate reflection of the coagulation status of the patient. It is recommended that for non-lesional biopsies, in patients with liver disease, a transvenous route should be used if the international normalised ratio (INR) is $>1.4$. For percutaneous lesional biopsies, the INR should be $<2.0$. There is no evidence that fresh frozen plasma is effective in reducing bleeding and is not recommended.

Most liver biopsies are obtained by radiologists, but there is little clear evidence that this is associated with reduced complications or increase in adequate samples.

Although there is little convincing evidence that obtaining percutaneous liver biopsy under imaging guidance reduces complications, we recommend that where possible, liver biopsy should be obtained under ultrasound guidance; where this is not appropriate, we recommend that the liver should have been imaged within 3 months of the biopsy (or more recently if there has been any change in the condition of the patient) to enable planning of the optimal biopsy site.

We recommend the use of automated cutting-type needles and that full core biopsy needles are used, provided that the operator is sufficiently experienced in the use of these needles. We recommend that a $16 \mathrm{G}$ needle should be used for the percutaneous approach, although an $18 \mathrm{G}$ needle should be used for percutaneous biopsy of a solid lesion, and the length of the sample should be at least $20 \mathrm{~mm}$.

There should be clear communication between the clinician requesting the biopsy, the person obtaining the biopsy and the histopathologist generating the report. The request form should include 
the indication(s) and all relevant clinical and other information to ensure that the procedure is done as safely as possible and that the histopathologist has all the necessary information. The biopsy report should clearly deal with the clinical indication(s) for the biopsy and conclude with a concise diagnostic summary. The report should be given in a timely fashion. For biopsies obtained outside a specialist liver centre, the reporting pathologist should have access to a second opinion from a liver centre.

\section{Research and audit questions}

In many aspects of liver biopsy, the evidence is weak. We recommend that there should be local and national audits for the major complications of liver biopsy; these should include evaluation of the various types of liver biopsy needle used to provide evidence for the safest and most effective needle units, and clinicians undertaking liver biopsies should ensure their own and centre's complication rates are within accepted range; we recommend that there should be national standards, evidence-based where possible, about the training and competencies of those obtaining liver biopsies; we recommend that there is further research into the haematological parameters that preclude safe percutaneous biopsies and into interventions to reduce the risk of bleeding after liver biopsy

\section{LIVER BIOPSY GUIDELINES: PATIENT/LAY SUMMARY}

A fuller lay summary is given in online supplementary material.

\section{Introduction}

A liver biopsy is a diagnostic test, which involves the removal of a small quantity of tissue from the liver, usually done under local anaesthetic, to allow microscopic examination of the liver.

\section{Purpose of a liver biopsy}

There are many causes of liver disease and it is sometimes difficult to diagnose and work out the best treatment using other tests such as non-invasive imaging techniques or blood tests.

The main reasons for a liver biopsy are to

- help clarify diagnosis;

- determine severity of liver damage or grade of tumour;

- help predict prognosis in a person with a known diagnosis;

- inform treatment decisions;

- monitor disease progression or response to treatment;

- obtain liver tissue for non-histological assessment (microbiology, biochemical, other);

- support research.

\section{Meeting patient concerns}

Some patients are anxious about having a biopsy, are unsure what it involves or why they have to have it, how long it takes or how much it is likely to hurt. The British Liver Trust has identified three key areas for improvement: communication, consent and post-biopsy information.

\section{Risks of having a biopsy}

Generally, liver biopsy is a safe procedure, but it is not free of risk. All invasive procedures have an associated risk of illness or disease (morbidity) or death (mortality). The reported risk of complications varies depending on the type of biopsy.

The risk of a biopsy needs to be balanced against the benefits that the findings of a biopsy will provide. The development of complications is not necessarily the fault or error of the healthcare professional. Some situations are associated with increased risk, such as where there is infection or obstruction in the liver or bile ducts, ascites (fluid in the abdomen) or pregnancy.

\section{Complications}

Complications are uncommon but there may be some mild pain or discomfort in the area of the biopsy. In a small number of cases there is some minor bleeding that soon stops.

After a biopsy, patients should seek medical advice when:

- Bleeding occurs from the site of the biopsy.

- The biopsy site becomes red, angry looking or swollen.

- A high temperature (fever) develops.

- The biopsy site is still painful after a few days and painkillers do not help.

In more severe and rarer cases, a blood transfusion and/or an operation is required to deal with the bleeding. On occasion it is possible for bile to leak from the liver internally. There is a small risk that the small wound will become infected after the biopsy.

\section{Different techniques for undertaking a liver biopsy}

There are various approaches to obtaining a liver biopsy.

\section{Percutaneous liver biopsy}

Percutaneous liver biopsy is the most common type of biopsy. It involves inserting a thin needle through the skin into the liver and removing a small piece of tissue. Before the procedure, you will be asked to lie on your back or on your left side. The skin over the liver region is then cleaned and prepared by applying antiseptic. Some local anaesthetic is then injected into a small area of skin and tissues just over a part of the liver (usually between two lower ribs on the right-hand side) to make the skin in this area numb. A special hollow needle is inserted through your skin into the liver. The clinician will ask you to breathe in and then out and then hold your breath while the needle is inserted into the liver. The needle will remove a small sample of liver tissue for further examination. The clinician obtaining the biopsy may be guided by an ultrasound scanner or CT scan for greater accuracy. Such scans are painless. Imaging can potentially reduce the risk of complications. Contrast-enhanced ultrasound may be of use in those with advanced chronic liver disease. ${ }^{1}$

A blind liver biopsy is where the biopsy is done without imaging guidance. The guidelines state that a blind liver biopsy should not be performed without recent liver imaging (within the preceding 3 months) and this imaging should be reviewed before undertaking a biopsy.

\section{Transvenous/transjugular biopsy}

A transvenous/transjugular biopsy is used in patients who have difficulty with blood clotting where there is a risk of bleeding.

You will be asked to lie on your back and the radiologist will apply a numbing medication on one side of the neck and makes a small incision. They then insert a flexible hollow tube (catheter) into the jugular vein. A contrast dye is then injected into the tube and a series of images taken. The dye allows the specialist to see the hepatic vein. A biopsy needle is then threaded through the tube and one or more liver samples are taken. The catheter is carefully removed, and the incision covered with a bandage.

Other types of liver biopsy include transfemoral (using the femoral vein as access point), endoscopic ultrasound-guided liver biopsy (done through an endoscope in the duodenum) and laparoscopic liver biopsy (through the abdomen, either during an operation or through a laparoscope).

\section{What care should you receive after your liver biopsy?}

Biopsies are usually done on the day and do not necessitate an overnight stay. You are expected to lie on your side and are observed for at least 3 hours to check there is no further bleeding. 
Any pain or discomfort experienced can usually be treated with painkillers.

The report may take 2 weeks or so to come back but if special tests are required, may be longer

\section{Informed consent}

Consent should be obtained from all patients prior to a liver biopsy in accordance with national guidelines. Consent must be voluntary, informed and the patient must have the mental capacity to decide. Information should be given orally and supplemented in written form using language that is comprehensible. The patient should be aware, in advance, of the benefits and risks of the procedure.

Where a biopsy is undertaken solely or partly for research purposes, patients must be fully informed and the procedure approved by the appropriate ethics committee/body in alignment with hospital regulations.

\section{Monitoring after the liver biopsy}

Patients are monitored so pain can be treated appropriately, and any complications detected and attended to early.

Discharge should happen only if your condition is stablethat is, when your circulation is acceptable/stable, there is no evidence of bleeding, blood pressure is normal and you do not have complaints of pain or shortness of breath.

Prior to discharge, you should be given oral and written instructions regarding further monitoring and day to day activities. This should include advice to rest and not drive motor vehicles, not to operate heavy machinery, not undertake strenuous activity or lift heavy objects for 48 hours.

If you experience any symptoms that would suggest discomfort, infection or injury, you should be instructed to contact the hospital and be provided with contact details how to do this.

\section{What happens to the sample after the liver biopsy?}

After the liver biopsy the sample is sent to a laboratory where it is assessed by a pathologist. It may take 2 weeks or more to obtain the report.

Samples from liver biopsies should be stored for 30 years. Reviewing biopsies over time can inform how the liver disease is progressing.

\section{Professional responsibility}

The decision to undertake a biopsy involves a number of clinicians with different specialist skills. You should have confidence that the decision to undertake a biopsy is correct and that the risks are carefully assessed.

All members of the team involved in the clinical decisionmaking should be aware of the risks and benefits in each individual case. Serious complications must be recorded and monitored.

Much clearer guidance on the competencies required and the training needed to undertake a liver biopsy should be developed.

\section{Quality standards}

For non-urgent biopsies, the interval between request and biopsy should be less than 4 weeks, regardless of which type of procedure is adopted.

All patients should be given oral and written information about the indications, benefits and risks of biopsy together with details of post-discharge support.

\section{INTRODUCTION AND BACKGROUND Current guidance}

The previous British Society of Gastroenterology (BSG) guidelines on the use of liver biopsy in clinical practice were published in $1999^{2}$ and modified in $2004 .^{3}$ Since that time, there have been many advances in the diagnosis, investigation and management of liver diseases. With the advent of newer serological and imaging techniques, the indications for liver biopsy have changed. Furthermore, as detailed in the section on 'Current practice', there have been changes in who does the liver biopsy, the needles available and use of imaging. There have also been advances in the development of new drugs for control of clotting and platelet function and greater understanding of the processes of haemostasis in liver disease. Therefore, it was agreed that the time was right for a complete review of the guidelines.

\section{Objective of guidance}

The objective of these revised guidelines is to provide healthcare professionals and patients clear recommendations on the role of liver biopsy in clinical adult practice.

\section{Development of guidelines}

The guidelines were developed under the auspices of the BSG and in lines with the BSG and National Institute for Health and Care Excellence (NICE) recommendations, following the Appraisal of Guidelines for Registration and Evaluation (AGREE) II . ${ }^{45}$ Because these guidelines affect several groups of healthcare professionals, they were developed in collaboration with the Royal College of Pathologists and the Royal College of RadiologistsThe group met on five occasions, and developed the content and agreed electronically. Individual members led the development of each section, using search terms including liver biopsy, histology, guidelines, blood coagulation disorders, haematological tests, bleeding risk assessment, coagulopathy, platelet function assay 100 (PFA-100), thromboelastogram, rotational thromboelastography (ROTEM), post-biopsy haemorrhage/bleed, invasive procedure, interventional radiology, biopsy, percutaneous. The guidelines have been reviewed by members of the liver section of the BSG. The final guidelines have been approved by all members of the guideline committee.

\section{Assessing the quality of guidelines}

The AGREE II instrument is an accepted method for appraising clinical guidelines. Six domains are listed.

\section{Scope and purpose}

The guidelines are intended for use by clinicians and other healthcare professionals, who may refer a patient for liver biopsy, who may obtain a liver biopsy, interpret the liver histology and care for the patient during and after the procedure. Guidance on liver biopsy was published by the BSG in 2004 and by the American Association for the Study of Liver Disease in $2009 .^{6}$

\section{Guideline Development Group (GDG) membership and stakeholder involvement}

Because these guidelines affect several groups of healthcare professionals, they were developed in collaboration with the Royal College of Pathologists, the Royal College of Radiologists and reviewed by the British Society of Haematology. Membership of the group includes gastroenterologists, hepatologists, interventional radiologists, histopathologists, nursing and patient representation. The guideline has been reviewed and ratified by the BSG liver section committee, the British Society 


\begin{tabular}{|c|c|}
\hline Certainty & Interpretation \\
\hline Very low & $\begin{array}{l}\text { The true effect is probably markedly different from the estimated } \\
\text { effect }\end{array}$ \\
\hline Low & The true effect might be markedly different from the estimated effect \\
\hline Moderate & $\begin{array}{l}\text { The authors believe that the true effect is probably close to the } \\
\text { estimated effect }\end{array}$ \\
\hline High & $\begin{array}{l}\text { The authors have a lot of confidence that the true effect is similar to } \\
\text { the estimated effect }\end{array}$ \\
\hline
\end{tabular}

of Gastroenterology, the Royal College of Radiologists and the Royal College of Pathologists.

\section{Rigour of development}

The published literature has been searched using PubMed, Medline, Web of Knowledge and the Cochrane database until February 2020. The GDG had a series of teleconferences and meetings and agreed revisions electronically. Individual members led on the development of each section, using search terms including liver biopsy, histology, guidelines, blood coagulation disorders, haematological tests, bleeding risk assessment, coagulopathy, PFA-100, thromboelastogram, ROTEM, postbiopsy haemorrhage/bleed, invasive procedure, interventional radiology, biopsy, percutaneous.

In accordance with the BSG advice on production of guidelines, the GDG applied the GRADE (Grading of Recommendations, Assessment, Development and Evaluations) system. Our grading of evidence was based on four levels of evidence and the strength of our recommendation (high, moderate, low or very low) (table 1). Areas of disagreement about the recommendation grade were discussed and, if necessary, voting by members of the guidelines group, although this was rarely required. Where possible, the health benefits, side effects and risks of recommendations have been discussed.

\section{Clarity and presentation}

Key recommendations are linked to discussion threads on a discussion forum hosted on the BSG website.

\section{Applicability}

Where necessary, we have discussed organisational changes that may be needed in order to apply recommendations. We have attempted to identify key criteria for monitoring and audit purposes.

Editorial independence and conflict of interest

Guideline group members have declared any conflicts of interest.

\section{Box 1 Purposes of liver biopsy}

Help clarify diagnosis

Determine severity of liver damage

Determine the nature and/or grade of tumour

Help predict prognosis in a person with a known diagnosis

Inform treatment decisions

Monitor disease progression or response to treatment

Obtain liver for non-histological assessment (microbiology,

biochemical, other)

Support research

\section{CURRENT PRACTICE}

\section{Clinical care}

Following recent improvements in non-invasive tests, the indications for liver biopsy have decreased, although histology still remains invaluable in diagnosis and management of selected patients. ${ }^{7}$ There is no consensus on best practice.

The UK guidelines issued by the BSG were revised in $2004 .^{23}$ Since then, there have been advances in technology that allow noninvasive assessment of the liver, better understanding of the clotting of blood and further information about the safety and risks of different needles. Review of practice around the UK (unpublished) suggests that the great majority of biopsies are obtained by radiologists under ultrasound guidance, but in a few centres some biopsies are still done on the ward without concurrent ultrasound guidance. There is considerable variation in many areas, such as the information given to patients, where the procedure is done, the haematological parameters allowing safe percutaneous biopsy, the competence required to do the biopsy, in the reporting of liver pathology and in professional accountability. An audit of the first 50 liver biopsies done in UK centres after 1 January 2008 showed that, of the 87 departments who responded, liver biopsy was done mainly by the radiologist (consultant $76 \%$, trainee 19\%, radiographer $<1 \%$ ), gastroenterologist (consultant $1 \%$, trainee $3 \%$ ), other $(1 \%){ }^{8}$

\section{The patient perspective}

More work needs to be done to make the approach to liver biopsy completely patient facing. Patients have much anxiety about the procedure, often with a lack of understanding of what is involved, how long it takes and how much it may hurt. In 2017-2018, of the 1807 liver health enquiries received by the British Liver Trust helpline services, 23 were related specifically to liver biopsies. The online support community forum has been operational since 2012, and more than 3500 posts have discussed liver biopsies. Recently, the British Liver Trust reviewed the helpline services enquiries, liaised with their support group facilitator and collated feedback regarding commonly expressed concerns relating to their experience of liver biopsy. Three main areas of concern were identified:

1. Communication: Patients report clinicians saying they 'needed a liver biopsy' but not explaining why or discussing any alternative medical investigations.

2. Consent: Patients highlighted the importance of being given enough time to discuss the indications fully, alternatives, risks and benefits of liver biopsy as part of the consent procedure in a safe, quiet area, prior to the procedure taking place. Where possible, this should not be on the same day as the procedure and patients should have an opportunity to discuss any concerns (with healthcare professionals and with relatives and friends) and have time to come back with any questions and queries. Patients also expressed a need for the consent to be taken by a healthcare professional who was knowledgeable about liver biopsies.

3. Postprocedure care: Patients often reported being given little or no discharge information after the procedure, especially about pain, what analgesia to take and when/where to seek medical help, if needed.

\section{INDICATIONS FOR LIVER BIOPSY}

Liver biopsy is usually done in one of two situations: for the assessment of diffuse liver disease or to diagnose a specific abnormality seen on cross-sectional imaging using a targeted biopsy. The purposes of a liver biopsy are outlined in box 1 . 


\begin{tabular}{|c|c|c|c|}
\hline Drug & Dose & Stop & Notes \\
\hline Clopidogrel, prasugrel, ticagrelor & & 7 Days & $\begin{array}{l}\text { If cannot delay for } 7 \text { days stop clopidogrel for } \\
24 \text { hours; platelet transfusion may be used but } \\
\text { transjugular liver biopsy route is recommended }\end{array}$ \\
\hline Aspirin & & 3-7 Days prior to elective procedures & $\begin{array}{l}\text { For urgent biopsies, aspirin can be continued at the } \\
\text { discretion of the clinician }\end{array}$ \\
\hline $\begin{array}{l}\text { Dual antiplatelet therapy-for example, } \\
\text { aspirin/clopidogrel }\end{array}$ & & $\begin{array}{l}\text { Consider if biopsy can be delayed or if } \\
\text { clopidogrel can be stopped. } \\
\text { Always continue aspirin }\end{array}$ & $\begin{array}{l}\text { Many patients receiving this antiplatelet combination } \\
\text { have cardiac stents }\end{array}$ \\
\hline Dipyridamole & & Omit on day of biopsy & \\
\hline \multirow[t]{2}{*}{ Low molecular weight heparin } & Prophylactic dose & 12 Hours before procedure & \\
\hline & Higher than prophylactic dose & 24 Hours before procedure & \\
\hline Direct oral anticoagulants & & Omit for 2 days before procedure & Omit for longer if dabigatran and renal impairment \\
\hline
\end{tabular}

Non-invasive methods to aid clinical decisions are preferred by patients rather than liver biopsy. ${ }^{9}$ With current virological, biochemical, serological and imaging investigations, many diagnoses and management decisions do not rely on histological information. As the indications for liver biopsy change, clinical teams need to ensure the decision to biopsy remains appropriate. Indications for liver biopsy in many conditions is outlined in specific guidelines. For disease-specific indications, see online supplementary appendix A.

A liver biopsy done for clinical (rather than research) purposes, can be justified only when

- The information gained is of value for management of the patient.

- The patient is fully informed about indications, risks, benefits, alternatives and follow-up plans and has given informed consent.

- The procedure is done as safely as practicable.

- The operator is competent to perform the technique.

- The sample(s) are of adequate quality and size.

- The biopsy is examined by a histopathologist sufficiently competent to interpret the histology.

The operator and the histopathologist must be given all the relevant information, and the histopathologist should have access to a specialist referral pathway for unusual or complex biopsies, including post-transplant biopsies. ${ }^{10}$ These topics are discussed in detail below.

Recommendations

- All healthcare professionals involved in requesting, obtaining and interpreting the liver biopsy need to be aware of the indication(s) for the biopsy (strength of recommendation STRONG; quality of evidence WEAK).

- Where a biopsy is done outside guidelines or protocols, there should be multiprofessional discussions (which should include histopathologists where appropriate) prior to biopsy, and the decision recorded in the medical notes (strength of recommendation STRONG; quality of evidence WEAK).

\section{CLINICAL SITUATIONS WITH INCREASED RISK OF LIVER BIOPSY (EXCLUDING HAEMATOLOGICAL ISSUES/ CONSIDERATIONS)}

Many contraindications to percutaneous liver biopsy are relative and were defined when different techniques and larger diameter needles were used.

\section{The uncooperative patient}

Patients may be unable to cooperate for a variety of reasons, including anxiety. During the process of obtaining a percutaneous liver biopsy, it is essential that the patient is cooperative as any untoward movement when the biopsy needle is in the hepatic parenchyma can lead to a tear of the liver and capsule, with subsequent significant bleeding and pain. If the patient is anxious, then sedation with midazolam can be considered, with no increased risk. ${ }^{11}$ General anaesthesia can be used when the risks are justified.

\section{Extrahepatic biliary obstruction}

Extrahepatic biliary obstruction is frequently stated to be a contraindication to liver biopsy because of the risks of biliary peritonitis, septicaemic shock and death. ${ }^{12}$ In one study, serious complications occurred in at least $2 \%$ of patients (including biliary peritonitis), and another study reported significant complications in 4\% following percutaneous liver biopsy. ${ }^{13}$ With current imaging techniques (specifically, magnetic resonance cholangiopancreatography and endoscopic retrograde pancreatography), liver biopsy should be done for biliary obstruction only when there is doubt about the diagnosis and the benefit to the patient outweighs the risk. ${ }^{14}$

Where the biliary tree is dilated, a transjugular approach should be used because of the risks of biliary leak.

\section{Bacterial cholangitis}

The risk of inducing peritonitis and septic shock after liver biopsy has made cholangitis a relative contraindication. Bacteraemia after percutaneous biopsy of a non-infected liver occurs in up to $14 \%$ of biopsies. ${ }^{1516}$

\section{Ascites}

Percutaneous biopsy of the liver in the presence of large volume ascites is considered a contraindication in many texts. The reasons for this vary and include technical challenges and the risk of uncontrollable bleeding into the ascites; however, the evidence for these concerns is weak. CT or ultrasound-guided liver biopsy in the presence of ascites does not seem to affect the complication rate. ${ }^{17} 18$

Notwithstanding these studies, if a liver biopsy is clinically indicated in a patient with large-volume ascites, an image-guided percutaneous biopsy following total paracentesis or a transjugular biopsy can be considered.

\section{Amyloidosis}

Because of early reports of haemorrhage and death of patients following liver biopsy, ${ }^{19}$ amyloidosis is often listed as a contraindication. ${ }^{20}$ One case series from 1961 showed an intraperitoneal bleed with conservative treatment in 1 of 18 patients. $^{21}$ Current publications estimate the mortality of a liver biopsy in 
patients with amyloidosis at up to $5 \%{ }^{22}$ However, in patients who have had a liver biopsy for investigation of abnormal liver tests and who were unexpectedly found to have amyloidosis, the mortality and complication rate is lower than generally quoted. Since almost all patients with clinically significant liver amyloidosis have hepatomegaly and are of AL type, absence of serum and urine monoclonal immunoglobulins and serum light free chains makes such a diagnosis very unlikely.

If amyloidosis is strongly suspected, the diagnosis should be made by subcutaneous fat or rectal biopsy since most cases of amyloid are systemic. However, if suspicion is low and in hepatomegaly of uncertain aetiology, a liver biopsy can be justified, and we recommend the transjugular route.

\section{Obesity}

In the obese patient, it may be difficult to identify the liver by percussion. In this situation, the biopsy should be done under ultrasound guidance and in many cases the transjugular route might be preferable.

\section{Pregnancy}

Liver histology is rarely required in the management of the pregnant patient but may be helpful in the diagnosis of new onset liver abnormalities. ${ }^{23}$ In one small study, there was a small increased risk of premature birth, but no stillbirth was reported. ${ }^{24}$ In some non-life-threatening clinical conditions, it may be reasonable to wait until delivery of the baby. Thus, the benefits of biopsy need to be balanced against the risks to the mother and baby.

\section{Focal lesions with a cystic element}

Modern imaging techniques can often identify and categorise benign cystic lesions of the liver. Focal liver lesions with a cystic element may communicate with several structures, including the biliary tree, increasing the risk of biliary peritonitis after biopsy. Diagnostic fine needle aspiration may be used to evaluate these lesions. ${ }^{25-28}$ In the biopsy of focal lesions, risks may be increased if the lesion is highly vascular: the degree of risk will depend on whether the solid element of the lesion can be accessed without going through the cyst with the needle. Thus, the risk:benefit ratio will depend on the characteristics of the lesion.

\section{Recommendation}

- Where possible, risks should be minimised (such as sedation, drainage of ascites, biliary decompression) but biopsy is justified when the risks are outweighed by the benefits (strength of recommendation MODERATE; quality of evidence MODERATE).

\section{TECHNIQUES AND PROCEDURAL CONSIDERATIONS FOR LIVER BIOPSY}

There are several methods by which a liver biopsy may be obtained, classified according to the access site for obtaining the biopsy.

\section{Operator and operator experience}

Historically, gastroenterologists or hepatologists obtained most liver biopsies, as a 'blind' procedure. With the increasing use of imaging to help obtain percutaneous liver biopsies (PLBs), most biopsies are obtained by radiologists or gastroenterologists who have adequate training with use of ultrasound scanning (USS) assistance or guidance. With more recent expansion of skills, other groups of operators, such as clinical nurse specialists and physician assistants, have become adept at carrying out liver biopsies. It is worth noting that, in the UK and some other countries, training in obtaining a liver biopsy is not a requirement for training in gastroenterology and hepatology, although training should include an understanding of the indications, procedures, benefits and risk. ${ }^{29}$ In the USA, training in liver biopsy is not a requirement for level 1 training in hepatology but is a mandatory part of the formal advanced training process. ${ }^{30}$

No randomised trials have explored the impact of operator experience on outcome of liver biopsies. Non-randomised studies have highlighted the importance of operator experience to improve safety and success of liver biopsy, although this has not always been shown, but studies have been relatively small. ${ }^{31}$ Although there is no defined minimum number, the 1991 BSG audit recorded a higher, though not significant, complication rate of $3.2 \%$ in operators who had performed fewer than 20 liver biopsies compared with $1.1 \%$ in operators who had performed $>100$ liver biopsies. ${ }^{32}$ Other large published series have demonstrated similar findings, suggesting operator experience improves the quality of sample obtained. ${ }^{33-36}$ These studies emphasise the importance of carrying out a high volume of liver biopsy procedures, supervised by an experienced operator, before embarking on the procedure unsupervised, irrespective of the clinical background of the operator.

\section{Recommendation}

- Hospital policies should include a formal process and governance framework to ensure an operator is suitably experienced to undertake liver biopsies independently (strength of recommendation STRONG; evidence HIGH).

\section{Percutaneous liver biopsy}

Percutaneous liver biopsy refers to a biopsy taken by inserting a needle directly through the skin into the liver parenchyma. This method of biopsy always breaches the liver capsule with the attendant risk of intraperitoneal bleeding. Classification is based on whether image guidance is used and whether the biopsy track is plugged at the end of the procedure.

Typically, a PLB can be done safely in a procedure room on a ward, in the imaging department or, when clinically necessary, by the bedside (portable). It is vital that the room is a clean environment suitable for undertaking minor procedures and has easy access to consumables required for performing the biopsy (procedure packs, biopsy needles, etc). If ultrasound guidance is being used, the procedure room should be able to house the ultrasound machine and have the facility to reduce the ambient lighting.

There should be access to interventional radiology services, on site or through formalised transfer pathways to a referral centre, in the event of haemorrhage requiring embolisation.

\section{Transthoracic and transabdominal liver biopsy}

For both these approaches the patient lies supine. The borders of the liver are usually defined by percussion or visualised by ultrasound, with the breath held in deep expiration. In most instances, the intercostal space in the mid-axillary line, midway between the dome and tip of the liver, is infiltrated with local anaesthetic and a tiny incision is made through the skin. Higher (more cephalad) punctures increase the risk of pneumothorax, whereas lower punctures increase the risk of non-target organ puncture (which may be associated with more risk to the patient). The biopsy needle is advanced into the chosen intercostal space immediately above the more inferior rib, to avoid injury to the intercostal neurovascular bundle. The patient again holds their breath in expiration. The needle is advanced towards the xiphisternum, parallel to the bed/table to reduce the risk of injury to 
the gall bladder or kidney. The subsequent procedure for taking the biopsy then varies according to whether the biopsy needle is of the aspiration or cutting type and according to the specific instructions for use for the individual device. After the biopsy procedure, the patient usually lies on their right-hand side or supine for a period of time and regular observation of pulse and blood pressure are made in order to detect complications early (see section 'Clinical considerations').

\section{Blind, ultrasound-assisted and image-guided liver biopsy}

The method of liver biopsy described in the section 'Transthoracic and transabdominal lover biopsy' is done without USS and is commonly referred to as a 'blind' biopsy. However, some form of contemporary imaging should be available and reviewed to ensure there are no anatomical variations or interposing structures that would affect the chosen skin entry point. Imaging, usually with US, can be used to assist identification of the optimal site for needle insertion immediately prior to the liver biopsy (US assisted) and also detect the presence of new onset ascites. The imaging can also be used in real time, usually with US or CT, to visualise and guide the needle to the optimal point for biopsy (image guided).

Truly blind PLBs have been reducing in number across the UK. There are still units where clinicians prefer blind PLB to image guidance. Depending on the skills and experience of the operator, blind PLB can be safe and effective in obtaining tissue samples. ${ }^{3738}$

\section{Use of imaging}

A randomised study demonstrated the safety of ultrasound assistance over a blind PLB,${ }^{39}$ with similar findings from a retrospective study ${ }^{40}$ However, another retrospective comparative study did not demonstrate any benefit in US-guided PLB compared with blind PLB. ${ }^{41}$ Ultrasound assistance can change the skin entry site chosen by the percussion method in up to $15 \%$ of procedures to avoid adjacent structures and identify a safe needle trajectory, ${ }^{42}$ thereby reducing both minor and major complications of liver biopsy, and increase diagnostic yield. ${ }^{43}$ However, there is no way of predicting cases that might selectively benefit from the use of USS. ${ }^{44}$ It is also not clear whether real-time ultrasound guidance further improves diagnostic yield or reduces complications compared with US assistance for non-targeted liver biopsy. ${ }^{45}$ Studies based on an economic analysis of the use of US have shown cost savings compared with blind PLB after taking into consideration the cost of treating complications. ${ }^{46} 47$

In the biopsy of focal liver lesions, image guidance, with either real time US, CT or MRI, is a necessity to place the needle accurately at the site of the lesion and obtain a relevant sample with a high degree of accuracy. ${ }^{48}$ Real-time US has also been used in conjunction with fusion imaging to enable successful biopsy of focal lesions not readily visible on B-mode ultrasound. ${ }^{49}$

If operators wish to do 'blind biopsies', we recommend that this is done only when an ultrasound has been done to exclude anatomical and other variants that may affect the optimal site for liver biopsy. There are no data from which the maximum safe interval can be deduced; we recommend that the interval between imaging the liver and obtaining a blind biopsy should be no more than 3 months, unless there has been a significant, relevant change in the patient's clinical state which indicates the need for more recent imaging.

\section{- Recommendations}

- Where possible, every unit offering PLB should use image assistance or image guidance to minimise complications (strength of recommendation STRONG; evidence WEAK).
- A blind liver biopsy should not be performed in the absence of any prior imaging of the liver and only then when a blind approach is justified by clinical or logistical reasons (strength of recommendation STRONG; evidence WEAK).

- Recent liver imaging (within the preceding 3 months in a patient with stable liver disease) should be available and reviewed prior to performing a blind liver biopsy (strength of recommendation; STRONG; evidence WEAK).

- Ultrasound assistance should be used to reduce the risk of complications of liver biopsy (strength of recommendation MODERATE; evidence WEAK).

- Image-guided liver biopsies should be used for targeting focal lesions or in patients with altered liver anatomy (such as split liver graft or prior liver resection) (strength of recommendation STRONG; quality of evidence WEAK).

\section{Choice of biopsy needle}

The liver specimen may be taken using either an aspiration needle (such as Menghini or Jamshidi) or cutting needle (Trucut type). The latter are needles with a side notch against which the liver tissue sits before an outer sheath cuts the liver specimen. Although traditionally manual biopsy needle systems were used, there is more general use of cutting biopsy needle guns with an automated firing sequence. More recently, biopsy devices which extract a full core of tissue the whole diameter and length of the needle have become available (full core biopsy needles).

With regard to needle type, a large study of 68276 percutaneous liver biopsies recorded a higher frequency of complications with a Tru-cut needle $(3 / 1000)$ than the Menghini needle $(1 / 1000) .{ }^{50} \mathrm{It}$ was also noted that haemorrhagic complications were seen only in patients with malignant disease and cirrhosis. This suggests that haemostasis post-biopsy is a multifactorial process, with the 'tamponade' effect of the liver parenchyma being at least as important as needle type or size. Animal studies have demonstrated more bleeding with larger needle gauge,${ }^{51}$ but this has not been replicated in randomised human studies. ${ }^{52}{ }^{53}$ Moreover, larger gauge needles provide biopsy samples that are more technically adequate and have better diagnostic accuracy, with no significant increase in complications. ${ }^{54-56}$ Findings of another study in 1192 patients suggested that the sample adequacy of Tru-cut needles was superior to that of Menghini needles, with no significant difference in complication rates..$^{57} \mathrm{~A}$ recent publication showed the superiority of the Biopince $16 \mathrm{G}$ needle compared with the Achieve $18 \mathrm{G}$ needle, with inadequate biopsies obtained in $2 \%$ and $48 \%$, respectively. ${ }^{58}$

The introduction of the full core biopsy needle has allowed a higher percentage of technically adequate samples to be obtained compared with traditional cutting needles of similar gauge, reducing the need for repeat biopsies, with similar complication rates. ${ }^{5960}$

\section{Recommendation}

- We recommend use of automated cutting type needles However, familiarity with the device should also be taken into consideration when choosing the needle (strength of recommendation MODERATE; evidence WEAK).

\section{Needle gauge and number of passes}

Studies have clearly demonstrated improved diagnostic yield with an increased number of needle passes. However, three or more passes significantly increased the risk of complications and morbidity. ${ }^{61-63}$ No association was seen between the number of passes and severity of complications in at least two large 
studies. ${ }^{6465}$ Factors associated with severe complications were patient age, hepatic malignancy and elevated INR.

All the common medical liver diseases have an inherent heterogeneity in the distribution of the histological features that are required to establish a diagnosis and to assess disease severity. The resultant sampling variability may therefore limit the accuracy of histological assessments, particularly if the sample obtained is small or fragmented. To ensure that the sample is representative, various studies have suggested that longer sample size, and consequentially, increased number of visualised complete portal tracts (CPTs), strongly influences eventual diagnosis and staging of liver disease. ${ }^{646-70}$ In 2014, the Royal College of Pathologists updated guidelines suggested minimum adequacy requirement for samples to be at least $10 \mathrm{~mm}$ long and containing six portal tracts. However, there is good evidence that the disease severity (both fibrosis stage and grade of inflammation) tends to be underestimated in biopsies that include fewer than 11 portal tracts per tissue section. To obtain an intact core with sufficient tissue, the current recommendation is for a biopsy of a minimum length of $20 \mathrm{~mm}$, obtained with a 16-gauge needle. ${ }^{1071}$ Assessment of shorter biopsies may be compromised, and an additional pass should be considered if the sample obtained by the first pass is less than $10 \mathrm{~mm}$ in length, or is between 10 and $20 \mathrm{~mm}$ in length if the purpose of the biopsy is to establish the fibrosis stage or investigate biliary disease.

This recommendation was supported in the American Association for the Study of Liver Diseases (AASLD) position paper. ${ }^{6} \mathrm{~A}$ retrospective study demonstrated a significantly higher number of portal tracts obtained with a $1.6 \mathrm{~mm}$ Menghini needle than with a $1.4 \mathrm{~mm}$ needle. ${ }^{55}$ This view was supported by other retrospective studies that compared different needle sizes. ${ }^{72-74}$ The wider biopsy sample also allows better characterisation of the relationship between portal tracts, which are about $0.8 \mathrm{~mm}$ apart (see section 'Pathological considerations'). However, one systematic review found poor correlation between sample size and number of CPTs. ${ }^{75}$ Studies comparing 16 G and 18 G Trucut biopsy needles have suggested improved biopsy samples with the larger gauge needles with a larger number of CPTs. ${ }^{5376}$ No doubt, partial core biopsy needles further reduce the actual width of tissue obtained due to the side notch, and theoretically a similar gauge full core biopsy needle should provide a wider sample with more visualised portal tracts. This was demonstrated in a retrospective comparative study with better samples and greater number of portal tracts in a $16 \mathrm{G}$ full core needle versus an $18 \mathrm{G}$ partial core needle. ${ }^{58}$ Further, there is concern about potential complications from increased number of passes to obtain adequate samples. However, this may be overcome by a full core biopsy with a long throw (eg, $30 \mathrm{~mm})$, which could provide an adequate sample in a single pass. No comparative studies have been identified between full core biopsy needles of different sizes.

\section{Recommendations}

- We recommend one pass for the biopsy unless the diagnostic yield is likely to produce insufficient material for a full histological examination (as outlined in the section 'Pathological considerations') (strength of recommendation MODERATE; evidence WEAK).

- We recommend that broader gauge, full core biopsy needles, wider than $18 \mathrm{G}$, should be used (if the operator has sufficient experience with the needle) for non-lesional indications (strength of recommendation STRONG; evidence MODERATE).

\section{Prophylactic antibiotics}

Evidence on the benefit of routine antibiotic prophylaxis for biopsies obtained from native or transplanted livers in patients with normal biliary anatomy is limited. At least two previous studies demonstrated that PLB is associated with a transient bacteraemia in $5-13 \%$ of cases. ${ }^{15} 16$ However, no clear evidence is available on the proportion of these that develop infective complications. One randomised study did not demonstrate any significant difference in infective complications in the groups with and without prophylactic antibiotics, and the study did not recommend routine antibiotic prophylaxis before PLB. ${ }^{77}$

Slightly more evidence is available in patients undergoing liver biopsy in the presence of a biliary-enteric anastomosis. The results of these studies are mixed, with no clear consensus. At least two retrospective series demonstrate significantly greater infective complications following PLB in transplant livers with biliary-enteric anastomosis, thus recommending routine antibiotic prophylaxis. ${ }^{78}$ At least two case-control studies around the same time reported findings to the contrary in patients with biliary-enteric anastomosis. ${ }^{80} 81$ Another case-controlled study suggested that infective risk was higher in biliary-enteric anastomosis only in the presence of overt or occult biliary obstruction/ stasis. $^{82}$

No randomised trials have been published to provide more conclusive evidence regarding routine antibiotic prophylaxis in PLB in either native or transplanted livers.

\section{Recommendation}

- Antibiotic prophylaxis should not be used routinely prior to PLB except in the presence of a biliary-enteric anastomosis or history of previous post-biopsy infective complications or in overt biliary sepsis (strength of recommendation MODERATE; evidence WEAK).

\section{Plugged liver biopsy}

Plugged liver biopsy is a modification of the percutaneous approach, first described in $1984 .{ }^{83}$ It has been advocated as an alternative method for obtaining liver tissue in patients with impaired coagulation or ascites where transjugular liver biopsy (TJLB) is not feasible, such as targeted biopsy of a focal liver lesion, or where appropriate facilities are not available. The technique involves placing a coaxial introducer needle within the liver under ultrasound guidance. The inner trocar is removed, and the biopsy is taken through the introducer using a cutting needle. Multiple needle passes can be made with only a single capsular puncture. The biopsy track is then plugged using gelatine sponge or another suitable agent, while withdrawing the introducer. It should be noted that the use of a plugged biopsy technique requires insertion of an introducer with an inner lumen the same gauge as the biopsy needle, thereby creating a hole in the liver capsule of a greater size than the biopsy needle itself. No randomised trials of PLBs and plugged PLBs are available to determine the benefit of tract plugging in the presence of impaired coagulation.

Since the original description of the technique, multiple retrospective studies have highlighted the safety of plugged liver biopsy using a variety of agents, such as gelatine sponge, ${ }^{84} 85$ fibrin sealant, ${ }^{86}$ cyanoacrylate glue ${ }^{87}$ or blood products such as fresh frozen plasma. ${ }^{88}$ There have been no randomised trials to demonstrate superiority of one plugging agent over another.

One randomised controlled trial involving 100 patients demonstrated that plugged PLB was quicker to perform, provided larger samples but had a marginally higher, though non-significant, risk of haemorrhage after biopsy than TJLB. ${ }^{89}$ 
A more recent retrospective comparative study also suggested slightly lower technical success rates using TJLB than with plugged biopsy, and TJLB was associated with a lower average core length and lower average number of specimens obtained, but both methods yielded sufficient tissue for a definitive diagnosis. No major complications occurred in either group. ${ }^{90}$

\section{Transvenous liver biopsy}

Disorders of coagulation and/or ascites are common in patients with liver disease. Under these circumstances, conventional percutaneous liver biopsy would be contraindicated because of the perceived increased haemorrhagic risk. A transvenous route provides an alternative approach to liver biopsy, which potentially avoids breach of the liver capsule and reduces the risk of bleeding.

A transvenous biopsy requires the use of fluoroscopic guidance and needs to be performed in an angiography suite in the interventional radiology department. Inherently, these rooms are clean environments, often theatre grade, suited for performing such invasive angiographic procedures.

\section{Transjugular liver biopsy}

A TJLB is the favoured transvenous approach when a percutaneous liver biopsy is contraindicated or when additional investigations such as hepatic venography or hepatic vein pressure studies are also required. As with percutaneous biopsies, needles in TJLB sets are either of the aspiration type or cutting type. Previous cross-sectional or ultrasound imaging is usually sufficient prior to TJLB in providing information about patency of hepatic veins and their anatomical relations. The procedure is performed with ECG monitoring because of the risk of arrhythmias as the right atrium is traversed. Internal jugular venous (IJV) access (preferentially on the right side) is gained under ultrasound guidance. The right hepatic vein is normally catheterised and a long sheath advanced into the hepatic vein. The appropriate biopsy set and needle are then placed in the midportion of the hepatic vein. To obtain the specimen, the whole system, once in the right hepatic vein, is rotated anteriorly and medially. The needle tip is then advanced a few millimetres beyond the sheath tip and the biopsy taken by either advancing the aspiration needle further into the liver parenchyma or firing the automated cutting needle. Specimens tend to be smaller and more fragmented than those obtained through a percutaneous approach, and therefore a minimum of two to three needle passes is usually required to obtain an adequate sample.

TJLBs are performed with dedicated kits that include long sheaths and $18 \mathrm{G}$ or $19 \mathrm{G}$ automated cutting-type biopsy needles of appropriate length (such as the Quick-Core biopsy needle, Cook Medical, Bloomington, Illinois, USA). An alternative needle sometimes used is the modified Ross aspiration biopsy needle. Multiple retrospective studies over the past few decades have all demonstrated the safety and diagnostic adequacy of TJLB with an automated cutting biopsy needle or modified Ross biopsy needle. ${ }^{89} 91$ Fragmentation of samples is a problem with both types of transjugular needles, however, less so with the cutting type, as demonstrated in randomised trials and casecontrol studies. ${ }^{92-94}$ Comparative studies demonstrate that while the diagnostic adequacy of the samples is higher through PLB, samples obtained by TJLB are sufficient to make a diagnosis and equally safe..$^{95-97}$ Thus, in the presence of contraindications to PLB, TJLB provides an equally safe and adequate technique to obtain liver tissue, with cutting-type needles being preferred over aspiration-type needles.
TJLB is associated with minor and major complication rates of $6.5 \%$ and $0.56 \%$, respectively, but unlike percutaneous biopsy, is uncorrelated with the number of passes. Mortality can occur from major haemorrhage $(0.06 \%)$ or ventricular arrhythmia $(0.03 \%)$. TJLB can be done relatively safely even if the clotting is significantly deranged. ${ }^{98} 99$

\section{Transfemoral liver biopsy}

A transfemoral approach may occasionally be used when a transjugular approach has failed or is not technically feasible, as in patients with internal jugular vein thrombosis. The procedure may be performed via an inferior accessory hepatic vein or by direct puncture through the hepatic portion of the inferior vena cava. ${ }^{100}$ Alternative techniques, to obtain specimens from one of the main hepatic veins using endoscopic forceps, has also been described. ${ }^{101}$

\section{Endoscopic ultrasound (EUS) guided liver biopsy}

With increasing experience in the use of EUS in the liver, several series have reported its use in performing both non-targeted and targeted liver biopsies, with diagnostic yield of $90-100 \%$ and a low complication rate, even when using $19 \mathrm{G}$ needles. ${ }^{102-104}$ One recent retrospective, non-randomised, single-centre study ${ }^{105}$ of 90 patients found that the biopsy specimens obtained by the percutaneous route, compared with the EUS route, gave significantly more portal tracts (13 vs 5) and were more likely to enable a histological diagnosis (100\% vs 93\%), although those patients in the ultrasound group had a significantly shorter hospital stay (median hospital stay 3 vs 4.2 hours) and reported less pain (median pain score 0 vs 3.5 ). A tip-core biopsy needle delivers bigger samples than fine-needle aspiration biopsy needles. ${ }^{106}$

\section{Laparoscopic liver biopsy}

The laparoscopic technique is long established and is used in patients with coagulopathy where TJLB is unavailable or has failed. It is also used when biopsy of a focal liver lesion is required in the setting of severe coagulopathy. It enables direct visualisation of the liver and coagulation of the biopsy site to control any bleeding. Previous cross-sectional imaging can inform the surgeon of any anatomical contraindications to laparoscopic biopsy, such as a large abdominal aortic aneurysm or adherent small bowel loops. A laparoscopic biopsy is performed in an operating theatre with appropriate infection control techniques.

Laparoscopic liver biopsy may be done via a conventional laparoscopy or mini-laparoscopy, with the latter performed under local anaesthesia and conscious sedation. ${ }^{107} 108$ Laparoscopic liver biopsy generally entails performing liver biopsy through the laparoscope port using a long cutting-type needle. There is limited literature on this technique; however, a retrospective comparative study comparing laparoscopic liver biopsy using cutting-type needles with a percutaneous blind liver biopsy with a Menghini needle demonstrated its superiority in diagnosing background diffuse liver disease in patients with hepatocellular carcinoma. ${ }^{109} \mathrm{~A}$ further randomised controlled trial of laparoscopic liver biopsy versus PLB showed that the former, combining both macroscopic and histological assessment, was more sensitive for the diagnosis of cirrhosis and had a similar safety profile. ${ }^{110}$

The complications of laparoscopic liver biopsy include those of the laparoscopy itself.

Open wedge liver biopsy is also very occasionally performed, mostly in the setting of bariatric surgery, although its usefulness 
remains unclear but may help to identify fatty liver disease (see online supplementary appendix). ${ }^{111} 112$

\section{Recommendations}

- We recommend that there should be agreed formal pathways for access, in a timely fashion, to a regional or tertiary centre that can offer these facilities when clinically indicated (strength of recommendation STRONG; evidence WEAK).

\section{MORBIDITY AND MORTALITY}

The indications, methods and practice of liver biopsy have evolved, so extrapolation of complications of the procedure to current practice must be done with caution. All invasive procedures have an associated risk of both morbidity and mortality, and thus the risks of biopsy need to be balanced against the benefits of having histology or other data to help manage the patient's condition. It must be emphasised that the development of complications does not necessarily imply error by the healthcare professional.

\section{PERCUTANEOUS BIOPSY}

Reported morbidity and mortality associated with percutaneous liver biopsy varies considerably. Reasons for this variation include the fact that many of the larger studies are retrospective, ${ }^{113114}$ indications and practice have changed over time, there is little consistency in the definitions of the complications and many studies do not distinguish between death as a direct consequence of the biopsy and death from other causes.

Mortality at 3 months after liver biopsy has been reported to be as high as $19 \%,{ }^{32}$ but many of these deaths are related to the underlying condition rather than the biopsy itself. In this audit of 1500 liver biopsies, 26 (1.7\%) were associated with bleeding: blood transfusion was required in $11(0.7 \%)$, one required laparotomy. The proportion of bleeding episodes was higher in those with prolonged clotting $(3.3 \%$ in those with INR $1.3-1.5 \%$ and $7.1 \%$ in those with INR $>1.5$ ); bleeding was also more common in those with raised serum bilirubin $(2.7 \%$ compared with $1.1 \%)$ and low platelet count $\left(<150 \times 10^{9} / \mathrm{L}\right.$; $2.9 \%$, compared with $1.6 \%$ in those with higher platelet counts). No difference in bleeding was found between guided and blind biopsies. With respect to mortality, two deaths were directly attributed to the biopsy and three additional deaths were possibly attributable to the biopsy; the authors concluded that the death rate attributable to the liver biopsy was between $0.13 \%$ and $0.33 \%$.

One of the largest studies was reported by Piccinino and colleagues in $1986,{ }^{50}$ where outcomes of 68276 liver biopsies in 36 liver units in Europe were retrospectively analysed. Of the bleeding complications, haemoperitoneum was reported in 22 $(0.032 \%)$, intrahepatic haematoma and haemobilia in $0.006 \%$ each and haemothorax in $0.022 \%$. Infection occurred in $0.01 \%$ all in association with a Menghini technique; perforation of other organs was reported as pneumothorax in $24(0.35 \%)$, lung puncture in $1(0.014 \%)$, colon puncture in $2(0.003 \%)$, kidney in $2(0.003 \%)$ and gall bladder in $8(0.012 \%)$, again all with Menghini technique. Six deaths $(0.009 \%)$ occurred, all in those with cirrhosis or neoplastic disease.

In a retrospective study in England, West and Card ${ }^{115}$ analysed the mortality associated with elective percutaneous liver biopsy in 61187 patients between 1998 and 2005. Overall all-cause mortality by 7 days after biopsy was 2 per 1000 biopsies (95\% CI 1.8 to 2.5 ), with rates as high as 12 per 1000 for patients investigated for cancer. Death within 7 days directly related to liver biopsy occurred, at most, every 1 in 10000 biopsies in patients investigated for liver disease or abnormal liver function test results. Major bleeding occurred in about 6 per 1000 biopsies.

A retrospective study from Australia ${ }^{35}$ examined records from 1398 patients over a 20-year period. Major complications were found in 12 (1.0\%): haemorrhage (10), bile leak and visceral perforation (1 each). Seven of these patients had an abnormal baseline coagulation profile; a significant risk for major haemorrhage $(p<0.001)$, resulting in three deaths. All deaths occurred in inpatients with major comorbidities. Minor complications occurred in $13.6 \%$ of patients: multiple passes were a significant risk factor. The effect of time was apparent: the rates of both bleeding and death were greater in the period 1986-1995 than 1996-2005 (bleeding with normal coagulation profile $0.5 \%$ vs $0.13 \%$; mortality $0.45 \%$ and $0.13 \%$, respectively).

A much larger retrospective study of 15181 percutaneous liver biopsies at the Mayo Clinic ${ }^{116}$ reported 70 cases of haemorrhage $(0.5 \%)$ that were Common Terminology Criteria for Adverse Events (CTCAE) grade 3 or greater, identified within 3 months of biopsy. The incidence of bleeding in patients taking aspirin within 10 days before biopsy was $0.6 \%$, which was not statistically different from the incidence of bleeding in those not taking aspirin (0.4\%). Significant associations were found between major bleeding and serum platelet count and INR $(p<0.001)$, although the association between major bleeding and the size of the biopsy needle was not significant $(p=0.97)$. A later study ${ }^{117}$ from the same institution examined complications in a large series of adult patients using image-guided liver biopsies. Of 6613 biopsies performed in 5987 adult patients, there were 49 acute and delayed major adverse events (0.7\%). The incidence of haematoma requiring transfusion and/or angiographic intervention was $0.5 \%$ (34); of infection $0.1 \%(8)$, and haemothorax $0.06 \%$ (4). No patient had a pneumothorax. Three patients $(0.05 \%)$ died within 30 days of liver biopsy, one being directly related to biopsy. Most of the major adverse events $(83 \%)$ presented acutely within 24 hours. More than two biopsy passes, platelets $\leq 50000 / \mu \mathrm{L}$ and female sex were statistically significant risk factors for post-biopsy haemorrhage.

In a study of 4275 liver biopsies in 2002, Myers et al ${ }^{118}$ reported a bleeding rate of $0.35 \%$ and a mortality of $0.14 \%$ (six patients, five of whom died from bleeding and one from aspiration pneumonia).

Firpi and colleagues, ${ }^{119}$ in a survey of 3214 biopsies, reported a death rate of $0.06 \%$ (one each from blood loss and haemothorax). They noted that the introduction of ultrasoundguided biopsy was associated with a fall in haemothorax from 8 $(0.2 \%)$ to nil.

Howlett $e t a l^{8}$ undertook a retrospective audit of liver biopsies in the UK in radiology departments and centres were asked to provide data on 50 consecutive liver biopsies. Eighty-seven (41\%) of 210 departments responded. Information was provided on 3496 cases (1225 for focal disease). Ultrasound guidance was the most commonly used technique. Four haemorrhage-related deaths occurred $(0.11 \%$, all in patients with targeted biopsies for malignancy). Fifteen additional patients experienced at least one major complication: haemorrhage in 14 , haemobilia in 2: extrahepatic organs punctured included kidney, lung, gall bladder and bowel (one case each). Post-biopsy procedures included transfusion (12), percutaneous draining (4), laparotomy (1) and embolisation (2).

Gupta and colleagues, ${ }^{120}$ on behalf of the Society of Interventional Radiology, reported complication rates of between $0.3 \%$ and $3.3 \%$ and divided complications in to minor (no therapy or nominal therapy (which included overnight stay for observation only)) and major complications (which included 
requiring therapy with hospital stay $<48$ hours, major therapy which required increased level of stay for $>48$ hours, long-term sequelae and death).

A recent meta-analysis of bleeding after percutaneous liver biopsy ${ }^{121}$ concluded that 'bleeding of any kind occurred in up to $10.9 \%$ of image-guided liver biopsies, with major bleeding episodes ranging from $0.1 \%$ to $4.6 \%$ and minor bleeding events occurring in up to $10.9 \%$ of biopsies. The overall rate of bleeding was $<2 \%$. Risk factors for increased risk of bleeding included patient age ( $>50$ years or $<2$ years), comorbidities and/or concurrent diagnoses and coagulation status. The rate of bleeding was $3.3 \%$ if the INR was $1.2-1.5 \%$ and $7.1 \%$ if the INR was $>1.5$. Operator experience $(>200$ biopsies/year vs $<50 /$ year) did not affect the post-biopsy bleeding rate. Procedure-related risk factors included needle size (cutting biopsy compared with fine needle aspiration) and the presence of a patent track on post-biopsy ultrasound. There was no difference in bleeding rates between targeted and non-targeted biopsies and number of needle passes. One of most recent metaanalyses of ultrasound-guided liver biopsy included 12481 patients enrolled in 51 studies. The subgroup analysis indicated that ultrasound-guided liver biopsy had a low major complication rate for core biopsies, with rates of 0.016 for $14 \mathrm{G}, 0.010$ for $15 \mathrm{G}$, and 0.002 for $20 \mathrm{G}$, and low minor complication rates of 0.001 for core biopsy. Remarkably, specific complication rates of bleeding, pain, pneumothorax, vasovagal reactions and death were all nil. ${ }^{122}$

Other studies in adults or children have reported major bleeding episodes occurring in up to $2.5 \%$ and minor bleeding in up to $15 \%{ }^{36} 4546123-126$ in patients undergoing blind or ultrasoundguided biopsies. Nonetheless, a small fall in haemoglobin is often seen, in the absence of overt signs of haemorrhage. ${ }^{127}$

\section{Transjugular liver biopsy (TJLB)}

Indications for TJLB are usually different from those of percutaneous biopsy so direct comparison of morbidity and mortality between the two approaches may lead to misleading conclusions. Kalambokis ${ }^{98}$ reviewed complications from TJLB in 64 series reporting 7649 TJLBs evaluating the quality of specimen and safety. Minor and major complication rates were $6.5 \%$ and $0.56 \%$, respectively, and increased in children, but not with additional passes. In adults, mortality was $0.09 \%$ (haemorrhage $0.06 \%$; ventricular arrhythmia $0.03 \%$ ).

In a Canadian retrospective review of 461 biopsies performed over a 7 -year period, Gamble ${ }^{128}$ reported minor complications such as neck pain, haematoma at the puncture site, or fever occurring in 79 patients (17.1\%). Two patients died, but the biopsy was considered a factor in one (overall mortality $0.5 \%$ ). Bleeding occurred from the puncture site in the neck in $8(1.7 \%)$, carotid artery puncture in $3(0.7 \%)$ and intraperitoneal haemorrhage in 4 (0.9\%). Capsular perforation occurred in 18 (3.9\%) and resolved with Gelfoam in 17. Modification of the technique by taking the biopsy with the catheter positioned centrally rather than wedged peripherally reduced the occurrence of capsular perforation without affecting the success rate.

An analysis by McAfee ${ }^{129}$ found the reported mortality of TJLB was 0 in three major centres and ranged from $0.1 \%$ to $0.5 \%$ in three other centres. Velt, ${ }^{130}$ in a series of 160 patients, recorded only one case of pneumothorax and no deaths. Kis, ${ }^{131}$ examining complications of 166 TJLBs in 141 haematopoietic stem cell transplants at one institution, reported three major complications (1.8\%), including one death. Complications may be greater in those biopsied after bone marrow transplantation. ${ }^{132}$

\section{Endoscopic ultrasound-guided biopsy}

Endoscopic ultrasound-guided liver biopsy (EUS-LB) may be a safe and effective alternative approach to percutaneous or transjugular biopsy in the evaluation of both benign and malignant diseases of the liver. It can offer higher resolution imaging of the liver and can detect smaller lesions than CT or US scans of the abdomen. Evidence suggests the superiority of EUS-LB for a targeted approach of focal lesions, with less sampling variability in heterogeneous parenchymal disease. ${ }^{133}$ Mohan and colleagues $^{134}$ recently published an analysis of a systematic review and meta-analysis of reports of complications of EUSguided liver biopsy. Of the nine study arms with 437 patients, the pooled rate of adverse events with EUS-LB was 2.3\% (95\% CI $1.1 \%$ to $\left.4.8 \%, \mathrm{I}^{2}=0\right)$. On subgroup analysis, the adverse events rate with a $19 \mathrm{G}$ fine needle aspiration (FNA) needle (vs other core biopsy needles) was $0.9 \%$ (vs $2.7 \%, \mathrm{p}=0.28$ ).

\section{Laparoscopic liver biopsy}

A retrospective study of 2731 consecutive patients undergoing diagnostic mini-laparoscopy at two university hospitals in Germany $^{135}$ found that major complications occurred in 1.0\% $(n=27)$ : these included delayed bleeding from the liver biopsy site or abdominal wall ( $0.7 \%$ of patients) and intestinal perforation $(0.3 \%$ of patients). Two patients died after severe haemorrhage (mortality $0.07 \%$ ); the other patients recovered without sequelae. The risk of bleeding was increased in patients with low platelets $(\mathrm{OR}=6.1)$, increased $\mathrm{INR}(\mathrm{OR}=8.9)$, cirrhosis $(\mathrm{OR}=1.9)$ and portal hypertension $(\mathrm{OR}=2.1)$. Logistic regression showed a significant correlation only for the concurrence of low platelets and increased INR; bootstrap analysis identified INR $>1.5$ as a significant predictor. Prior abdominal surgery did not carry a significant risk for intestinal perforation unless abdominal adhesions were present.

\section{Conclusions}

The reported risk of death and complications vary. Some of the variation can be attributed to the inherent limitations in large retrospective studies, the lack of agreed definitions of complications, the clinical condition of the patient, the type of biopsy procedure and changes in practice over time.

\section{Recommendation}

When obtaining consent from patients, clinicians must use local data where available, tailored to the patient's individual situation (strength of recommendation STRONG; evidence $H I G H)$.

\section{HAEMATOLOGICAL CONSIDERATIONS}

Since the publication of the previous version of these guidelines, there have been major advances in the understanding of coagulation in health and liver disease, in the methodologies available to assess different aspects of coagulation and treatments for anticoagulation. Guidelines have been developed by the British Society of Haematology ${ }^{136} 137$ and the American Gastroenterology Association. ${ }^{138}$

\section{Coagulation testing}

Understanding of the coagulation profile in liver disease has evolved since the previous guideline was written. Historically, it was assumed that the raised prothrombin time often seen in liver disease, commonly expressed as an INR, reflected a bleeding risk and that correction with plasma products, specifically fresh frozen plasma (FFP), would reduce/correct this haemostatic failure. However, more recent studies have shown quite the 
reverse; that there is often a prothrombotic state, and transfusion of FFP has been described as usually unnecessary, ineffective and potentially hazardous. ${ }^{139-145}$ A recent Cochrane review concluded that there is uncertainty about the utility and safety of prophylactic FFP use. ${ }^{146}$ Thus, use of FFP is rarely indicated.

Although there is reduced synthesis/consumption of many procoagulant proteins and reduced numbers of platelets, there is an increase in factor VIII and von Willebrand Factor and a reduction in natural anticoagulants. Haemostasis in chronic stable liver disease is often referred to as 'rebalanced' with a net effect of normal haemostasis or even a procoagulant state and this is reflected in more 'global' assays of coagulation in patients with chronic liver disease, such as thrombin generation and viscoelastic haemostatic assays. ${ }^{147-154}$ There appears to be a similar rebalancing in acute liver disease. ${ }^{155}$

The INR is only sensitive for fibrinogen, factor II, factor V, factor VII and factor X and does not test the haemostatic balance in a patient with liver disease. The INR has been shown to be a poor predictor of bleeding during liver transplantation, and this procedure is now often done without the need for blood product replacement. ${ }^{145156}$

There is also a paucity of data to recommend a 'safe' minimum platelet number for procedures in patients with chronic liver disease, and whether platelet transfusion is effective. ${ }^{150} 157158$ Common practice has been to consider transjugular over percutaneous biopsy in patients with a platelet count $<50 \times 10^{9} / \mathrm{L}$ and/ or to transfuse platelets. There is no clear evidence regarding the efficacy and safety of platelet transfusions under these circumstances and increments may be poor and short lived in patients with portal hypertension.

More recent studies of thrombopoietin receptor agonists (TPO-RAs) have been shown to reduce the need for platelet transfusion in patients with cirrhosis requiring elective invasive procedures. ${ }^{103138159160}$ It is plausible that TPO-RAs provides a more effective haemostatic effect than platelet transfusion. The treatment period required prior to biopsy is 9-14 days. Although not seen in all studies, TPO-RAs have been associated with an increased risk of thrombosis, including portal vein thrombosis, ${ }^{161}$ so should be used with caution in patients considered to be at higher risk of thrombosis, especially as these patients were excluded from trials. In the UK, NICE has recently concluded that lusutrombopag is recommended, within its marketing authorisation, as an option for treating severe thrombocytopenia (that is, a platelet count of $<50 \times 10^{9} / \mathrm{L}$ ) in adults with chronic liver disease having planned invasive procedures; no recommendations were made about avatrombopag until it has an agreed list price in the UK. ${ }^{162}$

In a large retrospective study of patients having percutaneous liver biopsy, ${ }^{163}$ implementation of less stringent preprocedural coagulation parameters (INR $\leq 2.0$, platelets $\geq 25 \times 10^{9} / \mathrm{L}$ ) was associated with fewer haemorrhagic complication rates and a significant decrease in preprocedural $\mathrm{FFP} /$ platelet administration in comparison with using historical cut-off points (INR $\leq 1.5$, platelets $\geq 50 \times 10^{9} / \mathrm{L}$ ). Of note, haemorrhagic complication rates did increase as the INR increased and platelet counts decreased, but preprocedural FFP and/or platelet transfusion did not have a significant effect on haemorrhagic complication rates. While the results of conventional clotting tests correlate poorly with duration of bleeding and blood loss following liver biopsy, ${ }^{164} 165$ some retrospective studies do show an increased bleeding with an elevated INR, ${ }^{32} 135$ although the INR is generally not an independent risk factor for bleeding. ${ }^{166}$ A plausible explanation is that changes in the INR and platelet count are a surrogate marker for liver fibrosis and portal hypertension, which in itself will be a risk factor for bleeding; however, attempts to correct these haemostatic changes may increase bleeding risk as haemostatic failure is not the underlying cause of bleeding and increasing the intravascular volume is likely to be counterproductive.

The recent guidelines from the American Gastroenterology Association ${ }^{138}$ include the recommendations that blood products should be used sparingly because they increase portal pressure and carry a risk of transfusion-associated circulatory overload, transfusion-related acute lung injury, infection transmission, alloimmunisation and/or transfusion reactions.

The following transfusion thresholds for management of active bleeding or high-risk procedures may optimise clot formation in advanced liver disease: haematocrit $\geq 25 \%$, platelet count $>50 \mathrm{x}$ $10^{9} / \mathrm{L}$, and fibrinogen $>120 \mathrm{mg} / \mathrm{dL}$. Commonly used thresholds for correction of the INR are not supported by evidence.

The large volume of fresh frozen plasma required to reach an arbitrary INR target, limitations of the usual target, minimal effect on thrombin generation, and adverse effects on portal pressure limit the usefulness of this agent considerably.

In contrast, decompensated liver disease with acute or chronic liver failure is associated with a progressive consumptive coagulopathy and hypofibrinogenaemia, often with hyperfibrinolysis. Spontaneous mucocutaneous and other bleeding manifestations may become evident at this stage. In one study, a platelet count $<30 \times 10^{9} / \mathrm{L}$, fibrinogen level $<0.6 \mathrm{~g} / \mathrm{L}$ and activated partial thromboplastin time values $>100 \mathrm{~s}$ were the strongest independent predictors for new onset of major bleeding. ${ }^{167}$ All but the most essential invasive procedures should be avoided under these circumstances. Acute kidney injury has also been associated with an increased risk of bleeding after paracentesis in patients with decompensated cirrhosis. ${ }^{168}$

Treatment with vitamin $\mathrm{K}$ should be considered in patients with an increased INR, which may in part reflect vitamin K deficiency; particularly in patients in intensive care, in patients with malnutrition, in patients using antibiotics and in patients with cholestatic liver disease. ${ }^{147169}$

Increasing evidence shows that viscoelastic assays can be used to assess haemostatic status in patients with liver disease, with evidence that this can result in a reduction in blood products transfused. ${ }^{170-174}$ This has become increasingly established in liver surgery but more recently for other procedures. In a small randomised trial, De Pietri ${ }^{175}$ showed that in patients with cirrhosis and an INR $>1.8$ and/or platelet count $<50 \times 10^{9} / \mathrm{L}$ requiring invasive procedures, a thromboelastogram-guided transfusion strategy led to a significantly lower use of blood products (17\% compared with 100\% transfusion in the standard of care group) without an increase in bleeding complications; only one major bleed occurred, which was in the standard of care group. This has been shown in other openlabel randomised studies. ${ }^{176}$ Viscoelastic testing has therefore been used successfully to reduce unnecessary prophylactic transfusions in patients with liver disease (in comparison with using the INR and platelet count). In contrast, in a single-centre randomised study of central venous catheter insertion in patients with cirrhosis, a thromboelastography-based strategy did not reduce blood transfusion compared with usual care; however, a restrictive protocol (no transfusion unless INR $>5.0$ or platelet count $<25 \times 10^{9} / \mathrm{L}$ ) reduced transfusion without an increase in bleeding. ${ }^{177}$ It should also be noted that these assays have not yet been shown to reliably predict bleeding in patients with liver disease. ${ }^{150} 178$ 


\section{Antiplatelet agents}

The British Society for Haematology has produced guidelines on perioperative management of anticoagulation and antiplatelet therapy, although there are no specific recommendations for patients requiring liver biopsy. ${ }^{137}$ There is increasing use of P2Y12 inhibitors in patients with vascular disease and after arterial stenting (such as clopidogrel/prasugrel/ticagrelor). The antiplatelet effect persists for up to 7-10 days. It is common practice to pause these drugs approximately 7 days prior to elective procedures associated with a bleeding risk. Data in relation to transcutaneous liver biopsy are insufficient to recommend otherwise, and the haemostatic effects of P2Y12 inhibitors may be difficult to reverse (table 2). In a study of 8172 percutaneous ultrasoundguided intra-abdominal interventions, the frequency of bleeding was reported as significantly higher in patients taking medication interfering with platelet function or coagulation. ${ }^{34}$ In one retrospective study of CT-guided liver biopsies, aspirin use within 10 days had no significant impact on bleeding ${ }^{116}$; however, there was insufficient detail to determine whether closer proximity to biopsy time was a risk factor. The haemostatic effects of aspirin are more readily reversed, and indirect evidence suggests that treatment with aspirin can be paused for a shorter period (such as 3 days) prior to invasive procedures. ${ }^{179} 180$ Empirical experience (such as with post liver transplant biopsies) suggests that pausing aspirin may not be necessary and should be at the discretion of the operator if urgent. As with all clinical decisions, the risks of stopping anti-platelet drugs must be carefully considered and, where appropriate, consultant advice sought, especially in patients with recent stents/percutaneous coronary intervention if the procedure cannot be delayed.

\section{Anticoagulants}

Warfarin should be stopped 5 days before the procedure with point-of-care testing before the procedure to ensure adequate reversal (table 2). Bridging treatment with low molecular weight heparin should be started if deemed necessary. ${ }^{137}$

Direct oral anticoagulant drugs should be stopped for 2 days prior to the day of the biopsy or longer if taking dabigatran, depending on the renal function. ${ }^{181}$

\section{Recommendations}

For a non-lesional liver biopsy, we recommend a transvenous approach if the INR is $>1.4$ (strength of recommendation MODERATE; evidence MODERATE).

If a percutaneous targeted biopsy is required in a patient with stable liver disease, an INR of 1.5-2.0 is not a contraindication; however, the risk of bleeding may be higher in the context of liver fibrosis and portal hypertension (strength of recommendation MODERATE; evidence MODERATE).

We recommend FFP should not be used to correct an INR $\leq 2.0$ prior to liver biopsy (strength of recommendation STRONG; evidence MODERATE).

We recommend that, where time allows, stopping aspirin 3 days prior to percutaneous biopsy should be considered, but the decision will depend on the indications for aspirin and the urgency of the biopsy (strength of recommendation MODERATE; evidence WEAK).

In patients with acute kidney injury or acute or chronic/ decompensated liver disease, we recommend that liver biopsy should be avoided whenever possible as these conditions are often characterised by a consumptive coagulopathy and low fibrinogen, so these patients are at high risk of bleeding. Laboratory parameters associated with a particularly high risk of bleeding include a platelet count $<30 \times 10^{9} / \mathrm{L}$, fibrinogen level
$<0.6 \mathrm{~g} / \mathrm{L}$ and activated partial thromboplastin times $>100$ s. If liver biopsy is necessary for clinical management, a transjugular route should be used (strength of recommendation STRONG; evidence MODERATE).

We recommend that vitamin $\mathrm{K}$ depletion should be corrected before liver biopsy (strength of recommendation STRONG; evidence WEAK).

We recommend that patients with a history of abnormal procedure-related bleeding, unrelated to portal hypertension, should be referred for specialist haematology assessment prior to biopsy (strength of recommendation STRONG; evidence WEAK).

The routine use of global haemostatic tests is not recommended at this time (strength of recommendation LOW; evidence WEAK).

Where the platelet count is $<50 \times 10^{9} / \mathrm{L}$, a transvenous approach is recommended, where possible (strength of recommendation STRONG; evidence MODERATE).

The effectiveness and risks of platelet transfusion for a platelet count $<50 \times 10^{9} / \mathrm{L}$ have not been established but can be considered (strength of recommendation MODERATE; evidence WEAK).

TPO-RAs are an alternative to platelet transfusion according to local protocol (strength of recommendation MODERATE; evidence $H I G H)$.

Recommendations: when to stop anticoagulants and antiplatelet drugs-see table 2 (strength of recommendation STRONG; evidence WEAK).

\section{GENERAL PRINCIPLES FOR INFORMED CONSENT}

Informed consent should be obtained from all patients prior to percutaneous liver biopsy in accordance with national and local hospital guidelines ${ }^{182}$ For consent to be valid, it must be voluntary and informed, and the person consenting must have the ability to make the decision.

Where possible, the patient should be given information in advance of the procedure. Ideally, information should be given verbally and supplemented by written or other media. Consent should be confirmed in writing prior to the biopsy procedure in accordance with individual hospital policies. Consent forms should be written in the patient's native language wherever possible and when this is not possible, there should be access to a competent interpreter to ensure adequate understanding by the patient of both the risks and benefits of the procedure and commands given to them during the biopsy.

Information should be given about the risks of the procedure and the benefits and alternative approaches (if any). When figures are presented to patients, it is better to avoid giving percentages or rates; instead, we recommend that information should be presented as 'of 1000 people like you undergoing liver biopsy, 4 will require a blood transfusion'). ${ }^{183}$

If an adult has the capacity to make a voluntary and informed decision to consent to, or refuse, the procedure, their decision must be respected.

Some patients may lack capacity to give informed consent. If a person is unable to make a decision, understand the information relevant to the decision, retain the information or communicate his or her decision (by any means), then special consent must be obtained. Capacity must be assessed prior to consent. If a person does not have the capacity to make a decision about their treatment and has not appointed a lasting power of attorney, the healthcare professionals treating them may go ahead with the procedure if they believe it is in the person's best interests in accordance with the relevant national and local guidance. 
The basis for the decision should be clearly documented in the patient's records.

\section{Liver biopsy solely for research purposes}

Material obtained from a liver biopsy taken specifically for research has provided invaluable information for understanding the pathogenesis and treatment of disease. However, when the patient will derive no direct therapeutic benefit from the procedure and will only accrue the risks of that procedure, the patient should be fully aware of this and give written consent.

If part of the liver biopsy done for diagnostic or therapeutic purposes is taken for research, or if additional passes will be done to obtain material for research purposes, the patient must be given this information and give full consent. The procedure will also need approval from the appropriate research ethics committee (or equivalent) and hospital board.

\section{Recommendations}

- Patients should be given information about the risks and benefits of the procedure, in advance of the procedure where possible (strength of recommendation STRONG; quality of evidence $H I G H)$.

- Information should be given verbally and supplemented by information in written form or other media using language understood by the patient (strength of recommendation STRONG; quality of evidence HIGH).

- Information on risks should be readily understood and the following is recommended 'of 1000 people like you having a liver biopsy, X will develop (complication)' (strength of recommendation MODERATE; evidence WEAK)

- Consent should be confirmed in writing and local and national guidelines followed (strength of recommendation STRONG; evidence HIGH).

- Where a liver biopsy is done solely or partly for research, patients must be fully informed, and the procedure must be approved by the appropriate research ethics committee (or equivalent) and hospital regulations (strength of recommendation STRONG; evidence HIGH).

\section{CLINICAL CONSIDERATIONS}

In assessing the patient for a liver biopsy, the clinician requesting the biopsy and the operator performing the liver biopsy need to ensure that, unless there is mental incapacity, the patient understands the purpose of the liver biopsy and has given properly informed consent, and the benefits of the findings of the biopsy justify the risks.

To ensure that the biopsy can be done as safely and effectively as possible, the healthcare professionals need to consider the factors indicated in box 2

\section{Role of antimicrobial prophylaxis}

See section 'Prophylactic antibiotics'. Routine antimicrobial prophylaxis is not indicated except in the presence of biliary sepsis or a Roux loop in a liver allograft.

\section{Percutaneous biopsy}

Practice varies as to whether patients should be advised to be nil by mouth before a biopsy; some centres advise a minimum of 2 hours' fast but there is little evidence on which to make a firm recommendation. ${ }^{6}$

For the procedure itself, the patient is normally supine, in a comfortable position, with the right hand resting comfortably behind the head or by their side. Where the patient is anxious, sedative medication may be used, according to local guidelines.

\section{Box 2 Issues when considering liver biopsy}

When requesting and when performing liver biopsy

What is the indication for the biopsy?

Current medication and allergies

Current and past medical history

Can the patient understand and follow simple instructions?

Can the patient comply with aftercare instructions-for

example, lying flat?

Have plans for after-care been established?

Is there increased risk for staff?

Review of recent blood tests:

full blood count, including platelets

clotting studies

renal and liver function

Review of imaging:

Shape and size of liver

Any abnormal anatomy?

Any evidence of ascites?

Other structural elements (such as atypically located

bowel or gall bladder, cysts, etc)

Handling of histological specimen? (for example, for

metabolic or microbiological studies)

When requesting liver biopsy

Is antimicrobial prophylaxis indicated

What approach is optimal

Is clotting/platelet support indicated and, if support required,

is this adequate?

Should drug regimen be modified

\section{Immediately prior to biopsy}

Is this the right patient? Usually three points of identification are required

Has the patient given fully informed consent and is the

consent current?

Are all relevant personnel present and does everyone understand their role?

Have antimicrobials or clotting factors been given, where appropriate, and, if so, when?

Has routine medication been modified (if appropriate)?

Is there established venous access?

Is all the necessary equipment present and working

effectively?

Is there appropriate emergency support?

Once the site of biopsy is identified, the skin should be cleaned and then the patient is given a local anaesthetic, typically with $1 \%$ lidocaine. Where appropriate, the anaesthetic should be infiltrated into the capsule. As the liver moves during respiration, breathing while the biopsy needle is in the liver may cause laceration and bleeding. As a consequence, patients are usually asked to hold their breath while the needle is in the liver. Although there is some variation in practice, most centres advocate the operator taking the biopsy when the patient has taken a deep expiration as this will reduce the risk of pneumothorax. Whichever cycle of respiration is chosen, it is important that the biopsy itself is done during the same part of the cycle as used to identify the optimal site of biopsy.

\section{Recommendation}

- Percutaneous liver biopsy for non-lesional indications should be done with the patient holding their breath in 
expiration (strength of recommendation MODERATE; quality of evidence LOW).

\section{After the procedure}

After the procedure the patient is instructed to remain in the recumbent position for the duration of the post-procedure monitoring. Some centres advocate that the patient should lie on their right side, in the belief that that the pressure of the liver will reduce the risk of bleeding. In one small study, ${ }^{184}$ this was associated with more pain but no difference in complications. The duration of monitoring will be up to 8 hours, but for the low-risk patient with no post-biopsy complications, 3 hours' observation is usually adequate, ${ }^{119}$ although one recent study suggested that 1 hour is enough to recognise all major complications. ${ }^{185}$

Liver biopsy observations include monitoring the patient's pulse rate and blood pressure every $15 \mathrm{~min}$ for the first hour, ${ }^{119}$ then every $30 \mathrm{~min}$ for 2 hours and then hourly for the remaining period. If the patient is hypotensive or tachycardic then they should receive $500 \mathrm{~mL}$ of $0.9 \%$ saline, unless contraindicated, and then re-evaluated.

The biopsy site should be checked every half hour for signs of bleeding.

Patients should be discharged only if they are haemodynamically stable with no evidence of bleeding, stable blood pressure and no new complaints of pain or shortness of breath. ${ }^{186}$

1. Before discharge, patients should be given oral and written instructions regarding further monitoring and daily activities. The information should also include details of who to contact and how to contact them, in the event of complications or other concerns. Instructions should include advice to rest for the remainder of the day and not drive any motor vehicles or operate any heavy machinery on the day of the biopsy. Strenuous physical activities such as running, contact sports or heavy lifting for 48 hours after the biopsy are discouraged, although the evidence for this recommendation is weak.

2. If a patient experiences any symptoms such as chills, high fever, difficulty breathing, excessive bright red bleeding from the biopsy site, severe chest, shoulder or abdominal pain, passing blood in the stool or increasing abdominal swelling, then they are instructed to call the hospital.

Recommendation

- Patients should be monitored for at least 3 hours after liver biopsy with regular clinical observations and measurement of blood pressure and pulse (strength of recommendation STRONG; evidence WEAK).

\section{Outpatient day case liver biopsy}

It is recommended that patients undergoing day case percutaneous liver biopsy should have no conditions that might increase the risk of biopsy; these include encephalopathy, ascites, malignancy, hepatic failure with severe jaundice or evidence of significant extrahepatic biliary obstruction, significant coagulopathies or serious diseases involving other organs, such as severe congestive heart failure or advanced age. ${ }^{187}$ Pragmatic issues that will affect the decision not to undertake day case biopsy includes the travel time between the hospital and patient's home (or place of recovery), domestic situation and time of day that the biopsy is done.

Patients with a strong suspicion of malignancy should not be biopsied as a day case because such patients may have a higher risk of haemorrhage than patients without cancer. ${ }^{65}$
Day case biopsy should be done only where there is speedy access to a diagnostic laboratory, blood bank and in-patient facilities and when there are staff to observe the patient after the biopsy.

\section{Recommendation}

- Liver biopsy may be safely done as a day case procedure if there are no increased risk factors and the patient can be looked after when they have left hospital, can seek appropriate advice and access appropriate medical help if needed (strength of recommendation STRONG; evidence WEAK).

\section{PATHOLOGICAL CONSIDERATIONS}

Liver histology continues to provide information for diagnosis and prognosis of the patient where this cannot be obtained by non-invasive means (see box 1). This can be achieved only if the biopsy is of sufficient length and quality and examined by a suitably experienced histopathologist.

The scope and use of non-invasive tests is increasing, radically altering the need for liver biopsy. In particular, the number of biopsies obtained to assess disease severity when the diagnosis is established is falling. However, liver histology remains useful when clinical parameters and non-invasive tests suggest that there is more than one potential aetiological agent or give conflicting information.

\section{Size of biopsy}

For medical liver biopsies, the core of tissue should be intact and of sufficient size to demonstrate the lobular architecture of the liver over several portal tracts. Portal tracts and hepatic veins are about $0.8 \mathrm{~mm}$ apart and therefore better seen on a biopsy of around $0.8-1 \mathrm{~mm}$ in diameter, such as is obtained using a 16 $\mathrm{G}$ needle. The size and integrity of the sample is particularly important when being taken to investigate the stage of fibrosis in chronic liver disease, ${ }^{188}$ or in diseases which affect the liver in a variable way-for example biliary disease. ${ }^{189}$ There is agreement that the minimum biopsy sample for clinical trials purposes should be $20 \mathrm{~mm}$ obtained with a $16 \mathrm{G}$ needle. ${ }^{71}$

Good evidence shows that a biopsy containing 10 or fewer portal tracts results in underestimation of both the severity of the fibrosis stage and of the inflammatory grade in chronic viral hepatitis. ${ }^{64}$ In this study by Colloredo and colleagues, the proportion of biopsies showing at least bridging fibrosis was reduced from $41 \%$ in biopsies $30 \mathrm{~mm} \times 1.4 \mathrm{~mm}$ to around $20 \%$ if the biopsy was as wide but $10 \mathrm{~mm}$ long, or $30 \mathrm{~mm}$ long but $1 \mathrm{~mm}$ wide. In another study, digital imaging was used to generate 'virtual biopsies' from a grid superimposed on resection specimens to find the size of biopsy required to reliably stage fibrosis. Modelling $2.5 \mathrm{~mm}$ increments $1 \mathrm{~mm}$ wide showed that a length of $25 \mathrm{~mm}$ was required to achieve a reproducible percentage area of fibrosis. ${ }^{66}$ The American Association for the Study of Liver Diseases (AASLD) position paper on liver biopsy recommends 'long and wide (an ideal size is $3 \mathrm{~cm}$ long after formalin fixation obtained with a $16 \mathrm{G}$ needle)'. ${ }^{6}$ Transjugular biopsies are indicated for patients with increased risk of complications (see section 'Morbidity and mortality') and/or when venous pressure studies are also required. Transjugular biopsy devices have a narrower gauge, usually $18-19 \mathrm{G}$ needles, and therefore require multiple passes. It has been shown that four passes are required for optimal specimens. ${ }^{190}$

Recently, FNA specimens from the liver obtained under endoscopic ultrasound guidance have been introduced. These are used in endoscopic biliary investigation for painful jaundice and generate narrow fragmented specimens which may be sufficient 
to suggest the cause of jaundice (obstructive, hepatitic, late stage chronic disease) when no specific obstruction by stone or stricture has been identified by the examination. ${ }^{134} 191$ FNA specimens are not usually suitable for full histological assessment of diagnosis or disease stage.

Both side-cut and end-cut needles are widely used across the UK. There is little published evidence comparing the quality of biopsy samples obtained from different needles. The number of portal tracts in a given length of biopsy is variable and cannot be predicted from the biopsy length. ${ }^{67} 76$ A $16 \mathrm{G}$ needle biopsy specimen was found to be intact significantly more often than with $18 \mathrm{G}$ biopsy needles (71\% compared with 24\%) and to contain double the number of complete portal tracts per length of biopsy. ${ }^{76}$ Based on the above standard of an adequate biopsy being $20 \mathrm{~mm}$ in length and including $>10$ portal tracts, inadequate $<10 \mathrm{~mm}$ and $<6$ portal tracts, with intermediate samples described as 'compromised', one audit showed an adequate rate of $24.7 \%$ and inadequate of $21.9 \%$ in biopsies between 2008 and 2011, which represented a significant improvement on pre-2008 figures. ${ }^{68}$ This study corroborated the effect of biopsy size on fibrosis stage, with cirrhosis diagnosed in 6.5\%, $11.0 \%$ and $14.6 \%$ of inadequate, compromised and adequate biopsies, respectively, while the proportion reported as no fibrosis was $27.1 \%, 12.1 \%$ and $7.3 \%$.

A second core may therefore be needed to provide sufficient biopsy tissue. There is concern that more than one pass for a medical liver biopsy increases the complication rate, although no clear evidence on this point exists. ${ }^{3561}$ Pragmatically, a second pass should be considered if the biopsy core is $<20 \mathrm{~mm}$ long and especially if the purpose of the biopsy is to investigate fibrosis stage or possible biliary disease.

The biopsy report should include both the length of the biopsy specimen, whether there is fragmentation and an approximate number of portal tracts. This gives an objective measure of the reliability of the sample. ${ }^{10}$ Some biopsy interpretation is possible even if the amount of liver tissue is small, but the pathologist should state in their report that the biopsy is too small to provide a full assessment of the liver disease.

\section{Handling of biopsy}

Routine needle core or wedge biopsies are submitted in formalin and are best sent free-floating rather than attached to blotting paper. Biopsies from patients with known risk of infection, including hepatitis B and C viruses, HIV and tuberculosis should be labelled according to the local generic policy for specimens with a danger of causing infection; in view of the small specimen size, needle core biopsies do not require additional time in fixative before processing.

Requests for fresh tissue sent for immediate frozen section analysis must be communicated in advance with the laboratory, with clear indications of the findings and procedures being undertaken. These will generally be biopsies of subcapsular lesions and sent as small wedges of tissue.

If the clinical differential diagnosis includes Wilson's disease, a separate core of tissue should be taken for copper estimation by the chemical pathology department; this should be wrapped in moistened paper, but not floating in formalin or saline. The same process would be used for iron content, but this is now rarely required. If the clinical diagnosis includes acute fatty liver of pregnancy, the liver biopsy should be sent fresh for frozen section for fat, since microvesicular steatosis in that condition may not be visible in fixed paraffin sections. Fresh samples for fat and freezing for metabolic disease may also be taken from paediatric patients; this is outside the scope of these guidelines. If a focal infective lesion/abscess is suspected, an additional fresh sample may also be sent to microbiology.

Detailed guidance for the processing, staining and reporting of liver biopsies is available in the Royal College of Pathologists 'Tissue pathways for liver biopsies' document. ${ }^{10}$

\section{Communication between clinician and pathologist} Information from clinician to pathologist

It is essential that the clinical indication/purpose for the biopsy is communicated to the reporting pathologist on the biopsy request form, to enable provision of a clinically useful report.

It must be clearly stated whether the biopsy is from a focal lesion or is non-targeted, obtained for investigation of diffuse liver disease; these two types of biopsy are handled differently in the laboratory so it is important that the staff who receive the biopsy are aware of its nature and ensure appropriate handling.

Results of relevant clinical investigations (including biochemistry, immunology and imaging, as appropriate) and a note of any previous liver biopsies should also be provided.

Pathologists often obtain additional clinical information from the electronic patient record, but the primary indication for biopsy may be obscured among a mass of information and should always be clearly specified on the request form. Furthermore, the biopsy may not be reported in the same institution as it was taken, so the additional source of information may not be available.

\section{Communication of findings}

For the primary reporting of medical liver biopsies, the reporting style and order of items included in the report are influenced by personal preference of the reporting pathologist/clinician. Items that are recommended to be included in all medical liver biopsy reports are listed in box 3 . Where appropriate, recognised scoring systems should be used (see online supplementary appendix).

\section{Pathology reporting}

Liver biopsies are received by most pathology departments in the UK and elsewhere. The Royal College of Pathologists tissue pathways document recommends that biopsies are reported by pathologists who have sufficient knowledge of hepatology to formulate a report that deals with the clinical question. Outside hepatology centres, it is recommended that there is a local lead histopathologist responsible for liver biopsies, and that the reporting pathologists work in close communication with local clinicians, ideally by a regular clinicopathological conference. This helps to maintain their expertise and to identify biopsies and cases which may benefit from a second opinion. They should have time for regular continuous professional development activity in liver pathology, and at least one member of the department should undertake some form of external quality assurance in liver pathology. When late post-transplant biopsies are taken in the patient's local hospital, it is recommended that these are referred to the relevant transplant centre for review.

For pathologists working in hepatology centres, there should be at least two consultants with specialist interest in liver pathology to ensure adequate cover, to support a regular clinical meeting for biopsy discussion and provide a referral service within the hepatology network. For transplant centres, a review service for transplant biopsies taken elsewhere should be provided.

There have been studies of circumstances when the original diagnosis on a liver biopsy is amended through specialist review as a result of clinical referral. Bejarano found major discrepancy in $28 \%$ that would affect management, and minor discrepancy 


\section{Box 3 Guide to the content of a histopathology report}

Clinical information received with the biopsy- including the indication/purpose of the biopsy. It is also useful to summarise any additional information available to the pathologist prior to the time of reporting, including information obtained from the electronic patient record and clinical discussion as appropriate.

Biopsy size/adequacy - expressed as length of biopsy core (on receipt in the department or on the tissue sections), number of fragments and an approximate number of portal tracts per section-to give an objective indication of the specimen quality.

Architecture- presence and severity of fibrosis, distortion of hepatocyte plates and vascular relationships, and parenchymal nodularity, as an indication of whether there is any chronic liver disease, if so whether there is bridging fibrosis or cirrhosis.

A systematic description of the histological abnormalities, including special stain findings (even when these are negative).

For medical liver biopsies an attempt should be made whenever possible to provide an indication of the main morphological pattern of liver disease.

Where appropriate (especially chronic liver disease) an indication of the severity of disease in terms of grade/stage. This can be by descriptive text or use of a scoring system appropriate to the disease, as preferred by local clinical practice.

Comparison with any previous liver biopsies, especially if the purpose of the biopsy is to investigate disease progression, or response to treatment.

A clinicopathological comment, including a note of any discussion with the responsible clinician. A concise, single line summary to conclude the report.

A SNOMED-CT code*

A record (including names) of any intradepartmental consultation, outside referral for second opinion and/ or discussion with clinician, if necessary, this may be as a supplementary report

*(SNOMED (Synchronised Nomenclature in Medicine) is a recognised structural vocabulary for use in an electronic clinical record. ${ }^{196}$

in 37\% biopsies; interpretation errors were the most common for chronic cholestatic disease and cirrhosis. ${ }^{192}$ More recently, Paterson found a discrepancy in 59\% of reviewed cases, although this included those sent for a second opinion as well as clinical referral, again with biliary disease as the the most common type of discrepancy and also highlighting issues with autoimmune disease and vascular abnormalities. A detailed clinical review found $61 \%$ of discrepancies affected clinical management. ${ }^{193} \mathrm{~A}$ third review found a discrepancy rate of $38 \%$ with $70 \%$ (26\% of all referred cases) assessed as having a major clinical impact. ${ }^{194}$

Many specialist groups and societies give advice on when to take a liver biopsy in various disease categories and awareness of these guidelines will help pathologists in constructing relevant reports (see online supplementary appendix A). It is strongly suggested that because of the challenges in diagnosis and also management implications, specialist review should be considered in new diagnoses of autoimmune disease, problematic biliary disease, including overlap entities and suspected vascular diseases, as a matter of routine.

\section{Timeliness of report}

For routine, non-urgent biopsies, it is recommended that cases are reported and authorised within 10 days of the biopsy being taken. However, variance from this may be appropriate so that all investigations can be completed and there has been an opportunity for clinicopathological discussion or if the biopsy has been referred elsewhere for reporting; an interim report may be issued in such circumstances.

For diagnostic biopsies where the report is required more urgently (eg, acute liver failure, transplant biopsies) a preliminary report should be given by telephone or email; the diagnosis and time/date of the provisional report, including a summary of any clinico-pathological discussion, should be recorded in the final report.

\section{Long term storage of biopsy specimens}

Review of previous biopsy material, sometimes going back over many years, can provide important information concerning the progression of liver disease, or of the nature of liver disease in a relative of a patient who may have an inherited disorder. Tissue blocks and glass microscope slides of tissue samples from living patients are normally stored for at least 30 years. If a shorter time is being considered, then blocks that provided the basis of a diagnosis of rare diseases or inherited genetic predisposition should be considered for permanent retention. In practice, it would be extremely laborious to select such material, and the histology archive is generally preserved for 30 years. ${ }^{195}$

\section{Recommendations}

- The clinical indication for liver biopsy should be clearly communicated to the reporting pathologist by the requesting clinician (strength of recommendation STRONG; evidence $H I G H)$.

- It must be clearly indicated if the biopsy is targeted at a focal lesion ('tumour biopsy') or taken for investigation of diffuse parenchymal disease ('medical liver biopsy') (strength of recommendation STRONG; evidence HIGH).

- For percutaneous medical liver biopsy, the specimen should be obtained with a $16 \mathrm{G}$ needle and measure $>20 \mathrm{~mm}$ in order to provide adequate tissue for examination. Consider a second pass if a smaller specimen is obtained, especially for investigation of fibrosis stage or possible biliary disease (strength of recommendation MODERATE; evidence HIGH).

- For targeted biopsy from a focal lesion, an $18 \mathrm{G}$ needle is recommended; we recommend that an additional biopsy is obtained from the non-lesional tissue (not adjacent to the lesion) to evaluate background liver disease and can be done using the same needle (strength of recommendation STRONG; evidence HIGH)

- We recommend that for transjugular biopsies, at least two biopsies are taken (strength of recommendation STRONG; quality of evidence HIGH).

- The biopsy report should clearly deal with the clinical indication for the biopsy and conclude with a concise diagnostic summary (strength of recommendation STRONG; quality of evidence HIGH).

- For biopsies obtained outside a specialist liver centre, we recommend that the reporting pathologist should have access to second opinion from a liver centre (strength of recommendation STRONG; quality of evidence HIGH).

\section{PROFESSIONAL RESPONSIBILITY}

The clinical decision to do a liver biopsy, to conduct the biopsy, process, analyse the sample and interpret it in the clinical context, to relay the report to the patient and make a management decision jointly with the patient is a complex process involving a number of clinicians with different specialist skills. The procedure itself has its own risks, but errors in other steps 
in this process can lead to the wrong diagnosis or management decision and has the potential to cause significant harm.

Many healthcare professionals are involved in the liver biopsy process so establishing clear accountability can be challenging. Each member of the team is accountable for the part they play. Clear communication of all relevant information is vital to the process. This may be difficult when those involved are in different locations. It is essential that the practitioners have access to all current relevant information. The practitioner obtaining the biopsy must be informed when new information becomes available that may alter the risk/benefit balance of the biopsy. The decision to obtain a liver biopsy involves balancing the risks of the procedure with the benefits gained; it should be noted that the operator, if not the responsible clinician, may not be in a position fully to assess the benefits and must rely on the advice of the clinician requesting the biopsy.

Hospitals and teams involved in the liver biopsy service should have internal clinical governance in place to audit and improve their quality and participate in external quality assurance and improvement programmes such as the Royal College of Physicians accreditation of liver units iQUILS (improvement of Quality In Liver Services) adopted in England and Wales.

Recommendation

- All members of the team involved in the clinical decisionmaking related to obtaining a liver biopsy should be aware of the risks and the benefit in each individual case, and hospitals must facilitate multidisciplinary and collaborative working as well as clinical quality assurance and improvement (strength of recommendation STRONG; evidence $H I G H)$.

- Serious complications including bile leakage, severe pain requiring additional hospitalisation, significant bleed requiring blood transfusion and death should be monitored on a local level (strength of recommendation STRONG; evidence WEAK).

\section{FUTURE RESEARCH}

Liver biopsy remains an important tool in the diagnosis and management of patients with abnormalities of liver tests and occasionally, in systemic disease; there is a small but significant risk of harm and even death. Newer technologies, such as incorporation of sensor arrays in the tip of biopsy needles (PMID: 31698304), may allow yet more information to be derived from a liver biopsy.

\section{Audit}

As practice is changing with the development of new diagnostic tests and investigations, and with new methodologies and technologies, lessons learnt from the past may be less relevant for providing informed consent. We suggest that

- There should be agreed standards nationally and internationally for the definitions of adverse effects.

- Both hospitals and professional organisations should conduct periodic audits of practice and outcomes; professional organisations should set up national databases for significant adverse events.

\section{Training and competencies}

- We recommend that there should be clear guidance for the establishment of competence for liver biopsy with respect both to training and current practice.

\section{Coagulation and bleeding}

As more is understood about the causes of bleeding after liver biopsy, we suggest that more research is required to
- Develop the most appropriate measure(s) of the risk of bleeding.

- Agree the safest way of managing a patient's need for ongoing anticoagulation or antiplatelet therapy and liver biopsy.

\section{Biopsy needles}

Technologies for taking liver specimens are improving and new needles are being introduced.

- We recommend that there should be more comparative audits that compare the efficacy of different needles with respect to safety, adequacy of specimen and cost.

\section{QUALITY STANDARDS}

- For non-urgent biopsies, the interval between request and biopsy should be less than 4 weeks, irrespective of approach (percutaneous, transvenous or other).

- All patients should be given oral and written information about the indication, benefits and risk of biopsy and details of post-discharge support.

- Percutaneous biopsies should be obtained using a $16 \mathrm{G}$ needle (except for lesional biopsies for which an $18 \mathrm{G}$ needle is recommended).

- A provisional report for non-urgent biopsies will normally be given within 10 days of biopsy.

\section{Author affiliations}

${ }^{1}$ Liver Unit, University Hospitals Birmingham NHS Foundation Trust, Birmingham, UK ${ }^{2}$ Department of Vascular Radiology, Leeds Teaching Hospitals NHS Trust, Leeds, UK

${ }^{3}$ Liver Unit, Royal Liverpool and Broadgreen Hospitals NHS Trust, Liverpool, UK

${ }^{4}$ Department of Histopathology, Cambridge University Hospitals NHS Foundation

Trust, Cambridge, UK

${ }^{5}$ British Liver Trust, Ringwood, UK

${ }^{6}$ Department of Gastroenterology, Gloucestershire Royal Hospital, Gloucester, UK

${ }^{7}$ Department of Pathology, University of Birmingham, Birmingham, UK

${ }^{8}$ Department of Radiology, Queen Elizabeth Hospital Birmingham, Birmingham, UK

${ }^{9}$ Department of Haematology, Queen Elizabeth Hospital, Birmingham, UK

${ }^{10}$ Patient Representative, London, UK

${ }^{11}$ Department of Pathology, St James University Hospital, Leeds, UK

${ }^{12}$ Department of Gastroenterology, Royal Alexandra Hospital, Glasgow, UK

Correction notice This article has been corrected since it published Online First. The last author's name has been corrected.

Twitter Rebecca West @LiverTrust

Acknowledgements The Guidance Development Group would like to thank Dr Rupert Ransford, Dr Dhiraj Tripathi and Simone Cort from the British Society of Gastroenterology, Tania Van Buren and Professor Mark Callaway from the Royal College of Radiologists and Dr Michael Osborn from the Royal College of Pathologists for their help and support.

Contributors All authors have contributed and approved the mauscriipt.

Funding The authors have not declared a specific grant for this research from any funding agency in the public, commercial or not-for-profit sectors.

Competing interests None declared.

Patient and public involvement Patients and/or the public were involved in the design, or conduct, or reporting, or dissemination plans of this research. Refer to the Methods section for further details.

Patient consent for publication Not required.

Provenance and peer review Not commissioned; externally peer reviewed.

Data availability statement There are no data in this work

Open access This is an open access article distributed in accordance with the Creative Commons Attribution Non Commercial (CC BY-NC 4.0) license, which permits others to distribute, remix, adapt, build upon this work non-commercially, and license their derivative works on different terms, provided the original work is properly cited, appropriate credit is given, any changes made indicated, and the use is non-commercial. See: http://creativecommons.org/licenses/by-nc/4.0/.

ORCID iD

James Neuberger http://orcid.org/0000-0002-6079-002X 


\section{REFERENCES}

1 Sparchez Z, Mocan T, Hagiu C, et al. Real-time contrast-enhanced-guided biopsy compared with conventional ultrasound-guided biopsy in the diagnosis of hepatic tumors on a background of advanced chronic liver disease: a prospective, randomized, clinical trial. Ultrasound Med Biol 2019;45:2915-24.

2 Grant A, Neuberger J. Guidelines on the use of liver biopsy in clinical practice. British Society of Gastroenterology. Gut 1999;45(Suppl 4):IV1-11.

3 Neuberger JGA, Day C, Saxseena S. Guidelines on the use of liver biopsy in clinical practice, 2004. https://www.bsg.org.uk/wp-content/uploads/2019/12/BSGguidelines-on-the-use-of-liver-biopsy-in-clinical-practice.pdf

4 Brouwers MC, Kho ME, Browman GP, et al. AGREEgree II: advancing Guideline development, reporting and evaluation in health care. CMAJ 2010;182:E839-42.

5 NICE. Developing NICE guidelines: the manual. NICE, 2018. https://www.nice.org. uk/process/pmg20/chapter/introduction-and-overview

6 Rockey DC, Caldwell SH, Goodman ZD, et al. Liver biopsy. Hepatology 2009:49:1017-44.

7 Khalifa A, Rockey DC. The utility of liver biopsy in 2020. Curr Opin Gastroenterol 2020;36:184-91.

8 Howlett DC, Drinkwater KJ, Lawrence D, et al. Findings of the UK national audit evaluating image-guided or image-assisted liver biopsy. Part II. Minor and major complications and procedure-related mortality. Radiology 2013;266:226-35.

9 Kan VY-M, Marquez Azalgara V, Ford J-AE, et al. Patient preference and willingness to pay for transient elastography versus liver biopsy: a perspective from British Columbia. Can J Gastroenterol Hepatol 2015;29:72-6.

10 Wyatt JH S, Bellamy C. Tissue pathways for liver biopsies for the investigation of medical disease and for focal lesions. The Royal College of Pathologists, 2014.

11 Alexander JA, Smith BJ. Midazolam sedation for percutaneous liver biopsy. Dig Dis Sci 1993;38:2209-11.

12 Loludice T, Buhac I, Balint J. Septicemia as a complication of percutaneous liver biopsy. Gastroenterology 1977;72:949-51.

13 Morris JS, Gallo GA, Scheuer PJ, et al. Percutaneous liver biopsy in patients with large bile duct obstruction. Gastroenterology 1975;68:750-4.

14 Paymani M, Zajko AB, Campbell WL. Bile leakage as a complication of liver biopsy in liver transplants. Abdom Imaging 1993;18:258-60.

15 Frock JLL, Ellis CA, Turchik JB, et al. Transient bacteremia associated with percutaneous liver biopsy. J Infect Dis 1975;131:S104-7.

$16 \mathrm{McCloskey} \mathrm{RV,} \mathrm{Gold} \mathrm{M,} \mathrm{Weser} \mathrm{E.} \mathrm{Bacteremia} \mathrm{after} \mathrm{liver} \mathrm{biopsy.} \mathrm{Arch} \mathrm{Intern} \mathrm{Med}$ 1973;132:213-5.

17 Little AF, Ferris JV, Dodd GD, et al. Image-guided percutaneous hepatic biopsy: effect of ascites on the complication rate. Radiology 1996;199:79-83.

18 Murphy FB, Barefield KP, Steinberg HV, et al. CT- or sonography-guided biopsy of the liver in the presence of ascites: frequency of complications. AJR Am J Roentgenol 1988;151:485-6.

19 Volwiler W, Jones CM. The diagnostic and therapeutic value of liver biopsies with particular reference to trocar biopsy. N Eng/ J Med 1947;237:651-6.

20 Lovat LB, Persey MR, Madhoo S, et al. The liver in systemic amyloidosis: insights from 123 I serum amyloid $\mathrm{P}$ component scintigraphy in 484 patients. Gut 1998:42:727-34.

21 Stauffer MH, Gross JB, Foulk WT, et al. Amyloidosis: diagnosis with needle biopsy of the liver in eighteen patients. Gastroenterology 1961;41:92-6.

22 Rowe K, Pankow J, Nehme F, et al. Gastrointestinal amyloidosis: review of the literature. Cureus 2017:9:e1228.

23 Heneghan MA, Cannon MD. Hepatic diagnostics in pregnancy: biopsy, biomarkers, and beyond. Hepatology 2018;68:401-3.

24 Ludvigsson JF, Marschall H-U, Hagström H, et al. Pregnancy outcome in women undergoing liver biopsy during pregnancy: a nationwide population-based cohort study. Hepatology 2018;68:625-33.

25 Bret PM, Fond A, Bretagnolle M, et al. Percutaneous aspiration and drainage of hydatid cysts in the liver. Radiology 1988;168:617-20.

26 Brunetti E, Kern P, Vuitton DA, et al. Expert consensus for the diagnosis and treatment of cystic and alveolar echinococcosis in humans. Acta Trop 2010;114:1-16.

27 Filice C, Pirola F, Brunetti E, et al. A new therapeutic approach for hydatid liver cysts. Aspiration and alcohol injection under sonographic guidance. Gastroenterology 1990;98:1366-8.

28 Kumar A, Chattopadhyay TK. Management of hydatid disease of the liver. Postgrad Med J 1992:68:853-6.

29 Joint Royal Colleges of Physicians Training Board. Specialty training curriculum for gastroenterology August 2010; 2013.

30 A journey toward excellence: training future gastroenterologists - The Gastroenterology Core Curriculum, third edition. Gastrointest Endosc 2007;65:875-81

31 Sandy NS, Hessel G, Bellomo-Brandao MA. Major complications of pediatric percutaneous liver biopsy do not differ among physicians with different degrees of training. Am J Gastroenterol 2020;115:786-9.

32 Gilmore IT, Burroughs A, Murray-Lyon IM, et al. Indications, methods, and outcomes of percutaneous liver biopsy in England and Wales: an audit by the British
Society of Gastroenterology and the Royal College of Physicians of London. Gut 1995:36:437-41.

33 Chevallier P, Ruitort F, Denys A, et al. Influence of operator experience on performance of ultrasound-guided percutaneous liver biopsy. Eur Radiol 2004;14:2086-91.

34 Strobel D, Bernatik T, Blank W, et al. Incidence of bleeding in 8172 percutaneous ultrasound-guided intraabdominal diagnostic and therapeutic interventions - results of the prospective multicenter DEGUM interventional ultrasound study (PIUS study). Ultraschall Med 2015;36:122-31

35 van der Poorten D, Kwok A, Lam T, et al. Twenty-year audit of percutaneous liver biopsy in a major Australian teaching hospital. Intern Med J 2006;36:692-9.

36 Westheim BH, Aagenæs I, Østensen AB, et al. Effect of operator experience and frequency of procedure performance on complication rate after ultrasound-guided percutaneous liver biopsies. J Pediatr Gastroenterol Nutr 2013;57:638-43.

37 Bazlul Karim ASM, Rahman M. Safety of blind liver biopsy. Indian J Pediatr 2004;71:899-901.

38 Szymczak A, Simon K, Inglot M, et al. Safety and effectiveness of blind percutaneous liver biopsy: analysis of 1412 procedures. Hepat Mon 2012;12:32-7.

39 Lindor KD, Bru C, Jorgensen RA, et al. The role of ultrasonography and automatic-needle biopsy in outpatient percutaneous liver biopsy. Hepatology 1996;23:1079-83.

40 DiTeodoro LA, Pudhota SG, Vega KJ, et al. Ultrasound marking by gastroenterologists prior to percutaneous liver biopsy removes the need for a separate radiological evaluation. Hepatogastroenterology 2013;60:821-4.

41 Akkan Cetinkaya Z, Sezikli M, Güzelbulut F, et al. Liver biopsy: ultrasonography guidance is not superior to the blind method. J Gastrointestin Liver Dis 2010;19:49-52.

42 Riley TR. How often does ultrasound marking change the liver biopsy site? Am J Gastroenterol 1999;94:3320-2.

43 Caturelli E, Giacobbe A, Facciorusso D, et al. Percutaneous biopsy in diffuse liver disease: increasing diagnostic yield and decreasing complication rate by routine ultrasound assessment of puncture site. Am J Gastroentero/ 1996:91:1318-21.

44 Ahmad M, Riley TR. Can one predict when ultrasound will be useful with percutaneous liver biopsy? Am J Gastroenterol 2001;96:547-9.

45 Manolakopoulos S, Triantos C, Bethanis S, et al. Ultrasound-guided liver biopsy in real life: comparison of same-day prebiopsy versus real-time ultrasound approach. J Gastroenterol Hepatol 2007;22:1490-3.

46 Pasha T, Gabriel S, Therneau T, et al. Cost-effectiveness of ultrasound-guided liver biopsy. Hepatology 1998;27:1220-6.

47 Younossi ZM, Teran JC, Ganiats TG, et al. Ultrasound-guided liver biopsy for parenchymal liver disease: an economic analysis. Dig Dis Sci 1998;43:46-50.

48 Ichim VA, Chira RI, Mircea PA, et al. Accuracy of endoscopic ultrasound-guided biopsy of focal liver lesions. Med Ultrason 2020;1:20-5.

49 Ahn SJ, Lee JM, Chang W, et al. Clinical utility of real-time ultrasound-multimodality fusion guidance for percutaneous biopsy of focal liver lesions. Eur J Radiol 2018;103:76-83.

50 Piccinino F, Sagnelli E, Pasquale G, et al. Complications following percutaneous liver biopsy. A multicentre retrospective study on 68,276 biopsies. J Hepatol 1986:2:165-73.

51 Gazelle GS, Haaga JR, Rowland DY. Effect of needle gauge, level of anticoagulation, and target organ on bleeding associated with aspiration biopsy. Work in progress. Radiology 1992;183:509-13.

52 Forssell PL, Bonkowsky HL, Anderson PB, et al. Intrahepatic hematoma after aspiration liver biopsy. A prospective randomized trial using two different needles. Dig Dis Sci 1981;26:631-5.

53 Tublin ME, Blair R, Martin J, et al. Prospective study of the impact of liver biopsy core size on specimen adequacy and procedural complications. AJR Am J Roentgenol 2018:210:183-8

54 Aribaş BK, Arda K, Ciledağ N, et al. Accuracy and safety of percutaneous US-guided needle biopsies in specific focal liver lesions: comparison of large and small needles in 1300 patients. Panminerva Med 2012;54:233-9.

55 Sporea I, Gherhardt D, Popescu A, et al. Does the size of the needle influence the number of portal tracts obtained through percutaneous liver biopsy? Ann Hepatol 2012;11:691-5.

56 Vijayaraghavan GR, Vedantham S, Rangan V, et al. Effect of needle gauge and lobe laterality on parenchymal liver biopsy outcome: a retrospective analysis. Abdom Imaging 2015;40:1223-9.

57 Colombo M, Del Ninno E, de Franchis R, et al. Ultrasound-assisted percutaneous live biopsy: superiority of the Tru-cut over the Menghini needle for diagnosis of cirrhosis. Gastroenterology 1988;95:487-9.

58 Hall TC, Deakin C, Atwal GS, et al. Adequacy of percutaneous non-targeted liver biopsy under real-time ultrasound guidance when comparing the Biopince ${ }^{\mathrm{TM}}$ and Achieve $^{\text {TM }}$ biopsy needle. Br J Radiol 2017;90:20170397.

59 Constantin A, Brisson M-L, Kwan J, et al. Percutaneous US-guided renal biopsy: a retrospective study comparing the 16-gauge end-cut and 14-gauge side-notch needles. J Vasc Interv Radiol 2010;21:357-61. 
60 Rivera-Sanfeliz G, Kinney TB, Rose SC, et al. Single-pass percutaneous liver biopsy for diffuse liver disease using an automated device: experience in 154 procedures. Cardiovasc Intervent Radiol 2005;28:584-8.

61 Chi H, Hansen BE, Tang WY, et al. Multiple biopsy passes and the risk of complications of percutaneous liver biopsy. Eur J Gastroenterol Hepatol 2017;29:36-41.

62 Maharaj B, Bhoora IG. Complications associated with percutaneous needle biopsy of the liver when one, two or three specimens are taken. Postgrad Med $J$ 1992;68:964-7.

63 Perrault J, McGill DB, Ott BJ, et al. Liver biopsy: complications in 1000 inpatients and outpatients. Gastroenterology 1978;74:103-6.

64 Colloredo G, Guido M, Sonzogni A, et al. Impact of liver biopsy size on histological evaluation of chronic viral hepatitis: the smaller the sample, the milder the disease. J Hepatol 2003;39:239-44.

65 McGill DB, Rakela J, Zinsmeister AR, et al. A 21 -year experience with major hemorrhage after percutaneous liver biopsy. Gastroenterology 1990;99:1396-400.

66 Bedossa P, Dargère D, Paradis V. Sampling variability of liver fibrosis in chronic hepatitis C. Hepatology 2003:38:1449-57.

67 Chan J, Alwahab Y, Tilley C, et al. Percutaneous medical liver core biopsies: correlation between tissue length and the number of portal tracts. J Clin Pathol 2010;63:655-6.

68 Fryer $\mathrm{E}$, Wang LM, Verrill C, et al. How often do our liver core biopsies reach current definitions of adequacy? J Clin Pathol 2013;66:1087-9.

69 Coral GP, Antunes ADP, Serafini APA, et al. Liver biopsy: importance of specimen size in the diagnosis and staging of chronic viral hepatitis. Rev Inst Med Trop Sao Paulo 2016;58:10.

70 Schiano TD, Azeem S, Bodian CA, et al. Importance of specimen size in accurate needle liver biopsy evaluation of patients with chronic hepatitis C. Clin Gastroenterol Hepatol 2005;3:930-5.

71 Kleiner DE, Bedossa P. Liver histology and clinical trials for nonalcoholic steatohepatitis-perspectives from 2 pathologists. Gastroenterology 2015;149:1305-8.

72 Brunetti E, Silini E, Pistorio A, et al. Coarse vs. fine needle aspiration biopsy for the assessment of diffuse liver disease from hepatitis $C$ virus-related chronic hepatitis. J Hepatol 2004;40:501-6.

73 Petz D, Klauck S, Röhl F-W, et al. Feasibility of histological grading and staging of chronic viral hepatitis using specimens obtained by thin-needle biopsy. Virchows Arch 2003:442:238-44.

74 Röcken C, Meier H, Klauck S, et al. Large-needle biopsy versus thin-needle biopsy in diagnostic pathology of liver diseases. Liver 2001;21:391-7.

75 Cholongitas $E$, Senzolo M, Standish $R$, et al. A systematic review of the quality of liver biopsy specimens. Am J Clin Pathol 2006;125:710-21.

76 Palmer T, Georgiades I, Treanor D, et al. Improved tissue sections for medical liver biopsies: a comparison of 16 vs $18 \mathrm{G}$ biopsy needles using digital pathology. J Clin Pathol 2014:67:415-9.

77 Sato S, Mishiro T, Miyake T, et al. Prophylactic administration of antibiotics unnecessary following ultrasound-guided biopsy and ablation therapy for liver tumors: open-labeled randomized prospective study. Hepatol Res 2009;39:40-6.

78 Bubak ME, Porayko MK, Krom RA, et al. Complications of liver biopsy in liver transplant patients: increased sepsis associated with choledochojejunostomy. Hepatology 1991;14:1063-5.

79 Larson AM, Chan GC, Wartelle CF, et al. Infection complicating percutaneous liver biopsy in liver transplant recipients. Hepatology 1997;26:1406-9.

80 de Diego Lorenzo A, Romero M, Durán F, et al. Bacteremia following liver biopsy in transplant recipients with Roux-en-Y choledochojejunostomy. Rev Esp Enferm Dig 1997:89:289-95.

81 Lowe LP, Greenland P, Ruth KJ, et al. Impact of major cardiovascular disease risk factors, particularly in combination, on 22-year mortality in women and men. Arch Intern Med 1998;158:2007-14.

82 Dronfield MW, Mead GM, Langman MJ. Survival and death from subdural haematoma on medical wards. Postgrad Med J 1977;53:57-60.

83 Riley SA, Ellis WR, Irving HC, et al. Percutaneous liver biopsy with plugging of needle track: a safe method for use in patients with impaired coagulation. Lancet 1984;2:436.

84 Tsang WK, Luk WH, Lo AXN. Ultrasound-guided plugged percutaneous biopsy of solid organs in patients with bleeding tendencies. Hong Kong Med J 2014:20:107-12.

85 Zins M, Vilgrain V, Gayno S, et al. US-guided percutaneous liver biopsy with plugging of the needle track: a prospective study in 72 high-risk patients. Radiology 1992;184:841-3

86 Chisholm RA, Jones SN, Lees WR. Fibrin sealant as a plug for the post liver biopsy needle track. Clin Radiol 1989;40:627-8.

$87 \mathrm{Kim} \mathrm{SJ}$, Won JH, Kim YB, et al. Plugged percutaneous biopsy of the liver in livingdonor liver transplantation recipients suspected to have graft rejection. Acta Radiol 2017:58:771-7.

88 Haaga J, Rahim S. Direct injection of blood products versus gelatin sponge as a technique for local hemostasis. Cardiovasc Intervent Radiol 2017;40:231-5.
89 Sawyerr AM, McCormick PA, Tennyson GS, et al. A comparison of transjugular and plugged-percutaneous liver biopsy in patients with impaired coagulation. J Hepatol 1993;17:81-5.

90 Atar E, Ben Ari Z, Bachar GN, et al. A comparison of transjugular and pluggedpercutaneous liver biopsy in patients with contraindications to ordinary percutaneous liver biopsy and an "in-house" protocol for selecting the procedure of choice. Cardiovasc Intervent Radiol 2010;33:560-4.

91 Smith TP, Presson TL, Heneghan MA, et al. Transjugular biopsy of the liver in pediatric and adult patients using an 18-gauge automated core biopsy needle: a retrospective review of 410 consecutive procedures. AJR Am J Roentgenol 2003;180:167-72.

92 Bañares R, Alonso S, Catalina MV, et al. Randomized controlled trial of aspiration needle versus automated biopsy device for transjugular liver biopsy. J Vasc Interv Radiol 2001:12:583-7.

93 Choo SW, Do YS, Park KB, et al. Transjugular liver biopsy: modified Ross transseptal needle versus quick-core biopsy needle. Abdom Imaging 2000;25:483-5.

94 Maciel AC, Marchiori E, de Barros SGS, et al. Transjugular liver biopsy: histological diagnosis success comparing the trucut to the modified aspiration Ross needle. Arq Gastroenterol 2003;40:80-4.

95 Chau T-N, Tong S-W, Li T-M, et al. Transjugular liver biopsy with an automated trucuttype needle: comparative study with percutaneous liver biopsy. Eur J Gastroenterol Hepatol 2002;14:19-24.

96 Hardman RL, Perrich KD, Silas AM. Single-institution results of image-guided nonplugged percutaneous versus transjugular liver biopsy. Cardiovasc Intervent Radiol 2011:34:369-75

97 Meng HC, Lin HC, Huang CC, et al. Transjugular liver biopsy: comparison with percutaneous liver biopsy. J Gastroenterol Hepatol 1994;9:457-61.

98 Kalambokis G, Manousou P, Vibhakorn S, et al. Transjugular liver biopsy--indications, adequacy, quality of specimens, and complications--a systematic review. J Hepatol 2007:47:284-94.

99 Sue MJ, Lee EW, Saab S, et al. Transjugular liver biopsy: safe even in patients with severe coagulopathies and multiple biopsies. Clin Trans/ Gastroenterol 2019;10:e00063.

100 Cynamon J, Shabrang C, Golowa Y, et al. Transfemoral transcaval core-needle liver biopsy: an alternative to transjugular liver biopsy. J Vasc Interv Radiol 2016;27:370-5

101 Khosa F, McNulty JG, Hickey N, et al. Transvenous liver biopsy via the femoral vein. Clin Radiol 2003;58:487-91.

102 Eskandari A, Koo P, Bang H, et al. Comparison of endoscopic ultrasound biopsy needles for endoscopic ultrasound-guided liver biopsy. Clin Endosc 2019:52:347-52

103 Hasan MK, Kadkhodayan K, Idrisov E, et al. Endoscopic ultrasound-guided liver biopsy using a 22-G fine needle biopsy needle: a prospective study. Endoscopy 2019:51:818-24.

104 Shah ND, Baron TH. Endoscopic ultrasound and the liver: current applications and beyond. J Hepatobiliary Pancreat Sci 2018;25:171-80.

105 Ali AH, Panchal S, Rao DS, et al. The efficacy and safety of endoscopic ultrasoundguided liver biopsy versus percutaneous liver biopsy in patients with chronic liver disease: a retrospective single-center study. J Ultrasound 2020;5. doi:10.1007/ s40477-020-00436-z. [Epub ahead of print: 05 Mar 2020].

106 Ching-Companioni RA, Diehl DL, Johal AS, et al. 19G aspiration needle versus $19 \mathrm{G}$ core biopsy needle for endoscopic ultrasound-guided liver biopsy: a prospective randomized trial. Endoscopy 2019;51:1059-65.

107 Denzer U, Helmreich-Becker I, Galle PR, et al. Liver assessment and biopsy in patients with marked coagulopathy: value of mini-laparoscopy and control of bleeding. Am J Gastroenterol 2003;98:893-900.

108 Poniachik J, Bernstein DE, Reddy KR, et al. The role of laparoscopy in the diagnosis of cirrhosis. Gastrointest Endosc 1996;43:568-71.

109 Al-Saigh AH. Superiority of laparoscopic guided needle biopsy over percutaneous blind needle biopsy in diagnosing hepatocellular carcinoma associated with cirrhosis. Saudi J Gastroenterol 1998:4:96-100.

110 Denzer U, Arnoldy A, Kanzler S, et al. Prospective randomized comparison of minilaparoscopy and percutaneous liver biopsy: diagnosis of cirrhosis and complications. J Clin Gastroenterol 2007:41:103-10.

111 Collins H, Beban G, Windsor J, et al. Safety and utility of liver biopsy during bariatric surgery in the New Zealand setting. Obes Surg 2020;30:313-8.

112 Mahawar KK, Parmar C, Graham Y, et al. Routine liver biopsy during bariatric surgery: an analysis of evidence base. Obes Surg 2016;26:177-81.

113 Lebrec D, Goldfarb G, Degott C, et al. Transvenous liver biopsy: an experience based on 1000 hepatic tissue samplings with this procedure. Gastroenterology 1982:83:338-40.

114 Sagnelli E, Felaco FM, Filippini P, et al. Influence of HDV infection on clinical, biochemical and histological presentation of HBsAg positive chronic hepatitis. Liver 1989;9:229-34.

115 West J, Card TR. Reduced mortality rates following elective percutaneous liver biopsies. Gastroenterology 2010;139:1230-7.

116 Atwell TD, Smith RL, Hesley GK, et al. Incidence of bleeding after 15,181 percutaneous biopsies and the role of aspirin. AJR Am J Roentgenol 2010;194:784-9. 
117 Boyum JH, Atwell TD, Schmit GD, et al. Incidence and risk factors for adverse events related to image-guided liver biopsy. Mayo Clin Proc 2016;91:329-35.

118 Myers RP, Fong A, Shaheen AAM. Utilization rates, complications and costs of percutaneous liver biopsy: a population-based study including 4275 biopsies. Liver Int 2008;28:705-12.

119 Firpi RJ, Soldevila-Pico C, Abdelmalek MF, et al. Short recovery time after percutaneous liver biopsy: should we change our current practices? Clin Gastroenterol Hepatol 2005;3:926-9.

120 Gupta S, Wallace MJ, Cardella JF, et al. Quality improvement guidelines for percutaneous needle biopsy. J Vasc Interv Radiol 2010;21:969-75.

121 Midia M, Odedra D, Shuster A, et al. Predictors of bleeding complications following percutaneous image-guided liver biopsy: a scoping review. Diagn Interv Radiol 2019;25:71-80.

122 Tian G, Kong D, Jiang Tian'an, et al. Complications after percutaneous ultrasoundguided liver biopsy: a systematic review and meta-analysis of a population of more than 12,000 patients from 51 cohort studies. J Ultrasound Med 2020. doi:10.1002/ jum.15229. [Epub ahead of print: 30 Jan 2020].

123 Douds AC, Joseph AE, Finlayson C, et al. Is day case liver biopsy underutilised? Gut 1995:37:574-5.

124 Padia SA, Baker ME, Schaeffer CJ, et al. Safety and efficacy of sonographic-guided random real-time core needle biopsy of the liver. J Clin Ultrasound 2009:37:138-43.

125 Riemann B, Menzel J, Schiemann U, et al. Ultrasound-guided biopsies of abdominal organs with an automatic biopsy system. A retrospective analysis of the quality of biopsies and of hemorrhagic complications. Scand J Gastroenterol 2000;35:102-7.

126 Syn W-K, Bruckner-Holt C, Farmer A, et al. Liver biopsy in a district general hospital: changes over two decades. World J Gastroenterol 2007;13:5336-42.

127 Karatzas A, Karamitros A, Paraskevopoulos I, et al. Haematocrit and haemoglobin decrease following image-guided percutaneous core needle biopsies. Clin Radiol 2020;75:158.e9-14.

128 Gamble P, Colapinto RF, Stronell RD, et al. Transjugular liver biopsy: a review of 461 biopsies. Radiology 1985;157:589-93.

129 McAfee JH, Keeffe EB, Lee RG, et al. Transjugular liver biopsy. Hepatology 1992;15:726-32.

130 Velt PM, Choy OG, Shimkin PM, et al. Transjugular liver biopsy in high-risk patients with hepatic disease. Radiology 1984;153:91-3.

131 Kis B, Pamarthi V, Fan C-M, et al. Safety and utility of transjugular liver biopsy in hematopoietic stem cell transplant recipients. J Vasc Interv Radio/ 2013;24:85-9.

132 Ahmed 0 , Ward TJ, Lungren MP, et al. Assessing the risk of hemorrhagic complication following transjugular liver biopsy in bone marrow transplantation recipients. J Vasc Interv Radiol 2016;27:551-7.

133 Shah AR, Al-Hanayneh M, Chowdhry M, et al. Endoscopic ultrasound guided liver biopsy for parenchymal liver disease. World J Hepatol 2019;11:335-43.

134 Mohan BP, Shakhatreh M, Garg R, et al. Efficacy and safety of EUS-guided liver biopsy: a systematic review and meta-analysis. Gastrointest Endosc 2019;89:238-46.

135 Frenzel C, Koch J, Lorenzen V, et al. Complications and risk factors in 2731 diagnostic mini-laparoscopies in patients with liver disease. Liver Int 2012;32:970-6.

136 Chee YL, Crawford JC, Watson HG, et al. Guidelines on the assessment of bleeding risk prior to surgery or invasive procedures. British Committee for Standards in Haematology. Br J Haematol 2008;140:496-504

137 Keeling D, Tait RC, Watson $\mathrm{H}$, et al. Peri-operative management of anticoagulation and antiplatelet therapy. $\mathrm{Br} J$ Haematol 2016;175:602-13.

138 O'Leary JG, Greenberg CS, Patton HM, et al. AGA clinical practice update: coagulation in cirrhosis. Gastroenterology 2019;157:34-43.

139 Alkozai EM, Lisman T, Porte RJ. Bleeding in liver surgery: prevention and treatment. Clin Liver Dis 2009;13:145-54.

140 Helenius-Hietala J, Åberg F, Meurman JH, et al. Oral surgery in liver transplant candidates: a retrospective study on delayed bleeding and other complications. Oral Surg Oral Med Oral Pathol Oral Radiol 2016;121:490-5.

141 Holland L, Sarode R. Should plasma be transfused prophylactically before invasive procedures? Curr Opin Hematol 2006;13:447-51.

142 Jia Q, Brown MJ, Clifford L, et al. Prophylactic plasma transfusion for surgical patients with abnormal preoperative coagulation tests: a single-institution propensity-adjusted cohort study. Lancet Haematol 2016;3:e139-48.

143 Müller MC, Arbous MS, Spoelstra-de Man AM, et al. Transfusion of fresh-frozen plasma in critically ill patients with a coagulopathy before invasive procedures: a randomized clinical trial (CME). Transfusion 2015;55:26-35. quiz 25.

144 Rassi $A B$, d'Amico EA, Tripodi $A$, et al. Fresh frozen plasma transfusion in patients with cirrhosis and coagulopathy: effect on conventional coagulation tests and thrombomodulin-modified thrombin generation. J Hepatol 2020;72:85-94.

145 Westerkamp AC, Lisman T, Porte RJ. How to minimize blood loss during liver surgery in patients with cirrhosis. HPB (Oxford) 2009;11:453-8.

146 Huber J, Stanworth SJ, Doree C, et al. Prophylactic plasma transfusion for patients without inherited bleeding disorders or anticoagulant use undergoing non-cardiac surgery or invasive procedures. Cochrane Database Syst Rev 2019;11:CD012745.

147 DeAngelis GA, Khot R, Haskal ZJ, et al. Bleeding risk and management in interventional procedures in chronic liver disease. J Vasc Interv Radiol 2016;27:1665-74.
148 Drolz A, Ferlitsch A, Fuhrmann V. Management of coagulopathy during bleeding and invasive procedures in patients with liver failure. Visc Med 2018;34:254-60.

149 Groeneveld D, Porte RJ, Lisman T. Thrombomodulin-modified thrombin generation testing detects a hypercoagulable state in patients with cirrhosis regardless of the exact experimental conditions. Thromb Res 2014;134:753-6.

150 Intagliata NM, Argo CK, Stine JG, et al. Concepts and controversies in haemostasis and thrombosis associated with liver disease: proceedings of the 7th International coagulation in liver disease conference. Thromb Haemost 2018;118:1491-506

151 Lisman T, Porte RJ. Rebalanced hemostasis in patients with liver disease: evidence and clinical consequences. Blood 2010;116:878-85.

152 Potze W, Porte RJ, Lisman T. Management of coagulation abnormalities in liver disease. Expert Rev Gastroenterol Hepatol 2015;9:103-14.

153 Tripodi A, Mannucci PM. The coagulopathy of chronic liver disease. N Engl J Med 2011;365:147-56.

154 Tripodi A, Salerno F, Chantarangkul V, et al. Evidence of normal thrombin generation in cirrhosis despite abnormal conventional coagulation tests. Hepatology 2005;41:553-8.

155 Stravitz RT, Lisman T, Luketic VA, et al. Minimal effects of acute liver injury/ acute liver failure on hemostasis as assessed by thromboelastography. J Hepatol 2012:56:129-36

156 Massicotte L, Thibeault L, Roy A. Classical notions of coagulation revisited in relation with blood losses, transfusion rate for 700 consecutive liver transplantations. Semin Thromb Hemost 2015;41:538-46.

157 Napolitano G, lacobellis A, Merla A, et al. Bleeding after invasive procedures is rare and unpredicted by platelet counts in cirrhotic patients with thrombocytopenia. Eur $J$ Intern Med 2017;38:79-82.

158 Violi F, Basili S, Raparelli V, et al. Patients with liver cirrhosis suffer from primary haemostatic defects? Fact or fiction? J Hepatol 2011:55:1415-27.

159 Kuter DJ, Allen LF. Avatrombopag, an oral thrombopoietin receptor agonist: results of two double-blind, dose-rising, placebo-controlled phase 1 studies. $\mathrm{Br} J$ Haematol 2018;183:466-78.

160 Peck-Radosavljevic M, Simon K, lacobellis A, et al. Lusutrombopag for the treatment of thrombocytopenia in patients with chronic liver disease undergoing invasive procedures (L-PLUS 2). Hepatology 2019;70:1336-48.

161 Afdhal NH, Giannini EG, Tayyab G, et al. Eltrombopag before procedures in patients with cirrhosis and thrombocytopenia. N Engl J Med 2012;367:716-24.

162 NICE. Lusutrombopag for treating thrombocytopenia in people with chronic live disease needing a planned invasive procedure. Technology appraisal guidance [TA617]; 2020.

163 Kitchin DR, del Rio AM, Woods M, et al. Percutaneous liver biopsy and revised coagulation guidelines: a 9-year experience. Abdom Radiol 2018:43:1494-501.

164 Ewe K. Bleeding after liver biopsy does not correlate with indices of peripheral coagulation. Dig Dis Sci 1981;26:388-93.

165 Thachil J. Relevance of clotting tests in liver disease. Postgrad Med J 2008;84:177-81.

166 Sandrasegaran K, Thayalan N, Thavanesan R, et al. Risk factors for bleeding after liver biopsy. Abdom Radiol 2016;41:643-9.

167 Drolz A, Horvatits T, Roedl K, et al. Coagulation parameters and major bleeding in critically ill patients with cirrhosis. Hepatology 2016;64:556-68.

168 Hung A, Garcia-Tsao G. Acute kidney injury, but not sepsis, is associated with higher procedure-related bleeding in patients with decompensated cirrhosis. Liver Int 2018;38:1437-41.

169 Stravitz RT, Kramer AH, Davern T, et al. Intensive care of patients with acute liver failure: recommendations of the U.S. Acute Liver Failure Study Group. Crit Care Med 2007:35:2498-508.

170 Durila M, Lukáš P, Astraverkhava M, et al. Tracheostomy in intensive care unit patients can be performed without bleeding complications in case of normal thromboelastometry results (EXTEM CT) despite increased PT-INR: a prospective pilot study. BMC Anesthesio/ 2015;15:89.

171 Leon-Justel A, Noval-Padillo JA, Alvarez-Rios Al, et al. Point-of-care haemostasis monitoring during liver transplantation reduces transfusion requirements and improves patient outcome. Clin Chim Acta 2015;446:277-83.

172 Smart L, Mumtaz K, Scharpf D, et al. Rotational thromboelastometry or conventional coagulation tests in liver transplantation: comparing blood loss, transfusions, and cost. Ann Hepatol 2017:16:916-23.

173 Tafur LA, Taura P, Blasi A, et al. Rotation thromboelastometry velocity curve predicts blood loss during liver transplantation. Br J Anaesth 2016;117:741-8.

174 Wang S-C, Shieh J-F, Chang K-Y, et al. Thromboelastography-guided transfusion decreases intraoperative blood transfusion during orthotopic liver transplantation: randomized clinical trial. Transplant Proc 2010;42:2590-3.

175 De Pietri L, Bianchini M, Montalti R, et al. Thrombelastography-guided blood product use before invasive procedures in cirrhosis with severe coagulopathy: a randomized, controlled trial. Hepatology 2016;63:566-73.

176 Vuyyuru SK, Singh AD, Gamanagatti SR, et al. A randomized control trial of thromboelastography-guided transfusion in cirrhosis for high-risk invasive liverrelated procedures. Dig Dis Sci 2019. doi:10.1007/s10620-019-05939-2. [Epub ahead of print: 13 Nov 2019]. 
177 Rocha LL, Neto AS, Pessoa CMS, et al. Comparison of three transfusion protocols prior to central venous catheterization in patients with cirrhosis: a randomized controlled trial. I Thromb Haemost 2020;18:560-70.

178 Zakeri N, Tsochatzis EA. Bleeding risk with invasive procedures in patients with cirrhosis and coagulopathy. Curr Gastroenterol Rep 2017;19:45.

179 Li C, Hirsh J, Xie C, et al. Reversal of the anti-platelet effects of aspirin and clopidogrel. J Thromb Haemost 2012;10:521-8.

180 Weightman WM, Gibbs NM, Weidmann CR, et al. The effect of preoperative aspirinfree interval on red blood cell transfusion requirements in cardiac surgical patients. J Cardiothorac Vasc Anesth 2002;16:54-8.

181 Douketis JD, Spyropoulos AC, Duncan J, et al. Perioperative management of patients with atrial fibrillation receiving a direct oral anticoagulant. JAMA Intern Med 2019. doi:10.1001/jamainternmed.2019.2431. [Epub ahead of print: 05 Aug 2019].

182 GMC. Consent: patients and doctors making decisions together, 2008.

183 David AL, Akintomide H. Presenting risk information in sexual and reproductive health care. J Fam Plann Reprod Health Care 2016;42:213-9.

184 Hyun CB, Beutel VJ. Prospective randomized trial of post-liver biopsy recovery positions: does positioning really matter? J Clin Gastroenterol 2005;39:328-32.

185 Liane B-J, Dooley G, Sarkar S, et al. One-hour recovery time in subjects undergoing percutaneous liver biopsy: a quality improvement and patient safety project. Cureus 2019;11:e5799.

186 Bicknell SG, Richenberg J, Cooperberg PL, et al. Early discharge after core liver biopsy: is it safe and cost-effective? Can Assoc Radiol J 2002;53:205-9.
187 Seeff LB, Everson GT, Morgan TR, et al. Complication rate of percutaneous liver biopsies among persons with advanced chronic liver disease in the HALT-C trial. Clin Gastroenterol Hepatol 2010;8:877-83.

188 Scheuer PJ. Liver biopsy size matters in chronic hepatitis: bigger is better. Hepatology 2003;38:1356-8

189 Garrido MC, Hubscher SG. Accuracy of staging in primary biliary cirrhosis. J Clin Pathol 1996;49:556-9.

190 Vibhakorn S, Cholongitas E, Kalambokis G, et al. A comparison of four- versus three-pass transjugular biopsy using a 19-G Tru-cut needle and a randomized study using a cassette to prevent biopsy fragmentation. Cardiovasc Intervent Radiol 2009:32:508-13.

191 Mok SRS, Diehl DL. The role of EUS in liver biopsy. Curr Gastroenterol Rep 2019:21:6.

192 Bejarano PA, Koehler A, Sherman KE. Second opinion pathology in liver biopsy interpretation. Am J Gastroenterol 2001:96:3158-64.

193 Paterson AL, Allison MED, Brais R, et al. Any value in a specialist review of liver biopsies? Conclusions of a 4-year review. Histopathology 2016:69:315-21.

194 Colling R, Verrill C, Fryer E, et al. Discrepancy rates in liver biopsy reporting. I Clin Pathol 2014:67:825-7.

195 Wilkins B. The retention and storage of pathological records and specimens. 5th edn. Guidance from The Royal College of Pathologists and the Institute of Biomedical Science, 2015.

196 NHS Digital. SNOMED CT; 2020 